\title{
An Estimated Model with Macrofinancial \\ Linkages for India
}

\author{
Rahul Anand, Shanaka Peiris, and \\ Magnus Saxegaard
}




\title{
IMF Working Paper
}

Asia and Pacific Department

\section{An Estimated Model with Macrofinancial Linkages for India}

\author{
Prepared by Rahul Anand, Shanaka Peiris, and Magnus Saxegaard ${ }^{1}$
}

Authorized for distribution by Laura Papi

January 2010

\begin{abstract}
This Working Paper should not be reported as representing the views of the IMF.

The views expressed in this Working Paper are those of the author(s) and do not necessarily represent those of the IMF or IMF policy. Working Papers describe research in progress by the author(s) and are published to elicit comments and to further debate.

This paper develops a small open economy dynamic stochastic general-equilibrium model with macrofinancial linkages. The model includes a financial accelerator--entrepreneurs are assumed to partially finance investment using domestic and foreign currency debt--to assess the importance of financial frictions in the amplification and propagation of the effects of transitory shocks. We use Bayesian estimation techniques to estimate the model using India data. The model is used to assess the importance of the financial accelerator in India and the optimality of monetary policy.
\end{abstract}

JEL Classification Numbers:E52, E58, E61

Keywords: monetary policy, financial accelerator, macro-financial linkages, optimal policy, bayesian estimation

Author’s E-Mail Address:ranand@imf.org; speiris@imf.org; msaxegaard@imf.org

\footnotetext{
${ }^{1}$ The authors wish to thank Kalpana Kochhar, Laura Papi, Andy Berg, Nicoletta Batini, Eswar Prasad, and participants at seminars at the IMF and ISI Delhi for their helpful comments and suggestions.
} 


\section{Introduction}

Among macroeconomic practitioners there is growing recognition of the linkages between the financial sector and the real economy and, in particular, the role that balance sheets play in the transmissions of shocks to the economy. These linkages were highlighted during the September 2008 global financial crisis and the resulting slowdown on the global economy. In particular, Bernanke and Gertler (1989) showed in a seminal paper that the presence of asymmetric information in credit markets and monitoring costs would make the external finance premium faced by borrowers dependent on the strength of their balance sheets (their net worth). Moreover, because of the procyclical nature of net worth, this premium would tend to fall during booms and rise during recessions. Bernanke, Gertler, and Gilchrist (1999) (BGG hereafter), Kiyotaki and Moore (1997), Carlstrom and Fuerst (1997), and others have since demonstrated that these financial frictions may significantly amplify both real and nominal shocks to the economy. In the literature, this link between the cost of borrowing and net worth has become known as the "financial accelerator".

In addition, Krugman (1999), Aghion, Bacchetta, and Banerjee (2001) and others have argued that exchange rate and interest rate fluctuationsthrough their effect on balance sheets-are likely to have more serious consequences in emerging market economies that in industrialized countries. A contributing factor to this is-as noted by Elekdag, Justiniano, and Tchakarov (2005)-that borrowers in emerging market economies tend to rely more on

foreign currency borrowing. In this setting, a depreciation could trigger a deterioration in the balance sheets of borrowers with a negative net open foreign exchange position, eroding their net worth and increasing the cost of borrowing. By reducing the demand for capital, this erodes the value of borrowers' existing capital stock and their net worth, putting further upward pressure on borrowing costs. Papers exploring the importance of the financial accelerator for emerging market economies dependent on foreign currency borrowing include Elekdag, Justiniano, and Tchakarov (2005) and Batini, Levine, and Pearlman (2009).

In this paper, we develop and estimate a small open-economy Dynamic Stochastic General Equilibrium (DSGE) model that incorporates the financial accelerator mechanism proposed by BGG in a setting where firms are able to borrow in both domestic and foreign currency. The model is estimated on post-1996 Indian data using Bayesian estimation techniques. This 
is, to our knowledge, the first attempt at estimating a DSGE model for India. India provides an interesting backdrop for our analysis. India's monetary policy framework has evolved considerably over the past decades (RBI 2009). In particular, the opening up of the economy in the early 1990s and financial sector liberalization has been reflected in changes in the nature of monetary management (Mohan 2004). The basic objectives of monetary policy-maintaining price stability and ensuring sufficient credit to support growth-have remained unchanged. However, the opening up of the capital account-while necessary for providing sufficient capital for investment purposes and for reducing the cost of borrowing-exposes the economy to sudden stops in capital flows. In particular, volatile capital flows and its impact on the exchange rate have implications not only domestic demand and inflation, but for financial stability, with the result that maintenance of financial stability is of increasing concern to the Reserve Bank of India (RBI) (Mohan 2004). In order to meet these multiple challenges, the RBI has switched from a more traditional monetary targeting framework to a indicator based approach which seeks to strike a balance between price stability and reducing exchange rate volatility. However, as noted in the Rajan report on financial sector reform (Rajan 2008), further refinements to the monetary policy framework may be necessary to cope with the rise in capital inflows.

Over the last 5 years capital inflows have more than quadrupled, amounting to nearly 10 percent of GDP in 2007 and far exceeding the current account deficit. There has also been significant volatility as highlighted by the sharp outflows during the last quarter of 2008 and first quarter of 2009 and the subsequent dramatic recovery. These sharp swings in capital flows makes it difficult for the RBI to strike a balance between its different objectives, resulting in spurts of exchange rate volatility when a particular level of the exchange rate becomes too difficult to sustain, either because of inflationary pressures or because sterilization operations become too costly or harder to manage (Rajan 2008).

The trade-offs policymakers face in the conduct of monetary policy will largely be determined by type of shocks hitting the economy and the strength of macro-financial linkages-in particular the role that capital flows and balance sheets play in the transmissions of shocks to the economy (IMF 2009). Given the key role played by the corporate sector-fuelled to a large extent by bank credit and increasingly external commercial borrowing (ECB) denominated in foreign currency-in India's rapid economic growth in recent years (Oura 2008), these macrofinancial linkages have likely grown in importance. 
In particular, the importance of bank credit as a source of financing increases the importance of corporates' net worth as a tool to mitigate asymmetric information in credit markets while rising ECBs makes the balance sheet of corporates more sensitive to exchange rate fluctuations.

At the same time, India is equipped with a large equity market whose development has to a large extent been fuelled by large inflows from foreign institutional investors (FIIs). IMF (forthcoming) shows that stock market capitalization-an commonly used indicator of corporates' net worth (see e.g. Christiano, Motto, and Rostagno (2007))-is one of the key determinants of the flow of ECBs. As a result, equity market developments-including the amount of inflows from FIIs-are likely to have a direct bearing on the cost of financing for corporates in India, further increasing the importance of macrofinancial linkages in the economy.

The rest of this paper is structured as follows. Section 2 presents the main components of the model. Section 3 briefly describes the data and the estimation methodology before we present the results of the estimation in Section 4. In section 5 we employ the estimated model to analyze the optimality of monetary policy in India before a final section concludes.

\section{The Model}

The model is an expanded version of the small open-economy DSGE model outlined in Saxegaard (2006b). The augmented model features a financial accelerator mechanism similar to that proposed by BGG to study the effect of financial frictions on the real economy. The model incorporates financial frictions by assuming that firms have to borrow at a premium over domestic and foreign interest rates to finance part of their capital acquisition cost as in Christensen and Dib (2006), and Gertler, Gilchrist, and Natalucci (2007). Under this framework, information asymmetry between lenders and borrowers creates the financial friction by establishing a link between the cost of borrowing and the financial health of the firms. The external finance premium, in turn, is inversely related to the net worth of the entrepreneurs. Figure 1 provides a visual representation of the estimated model. 


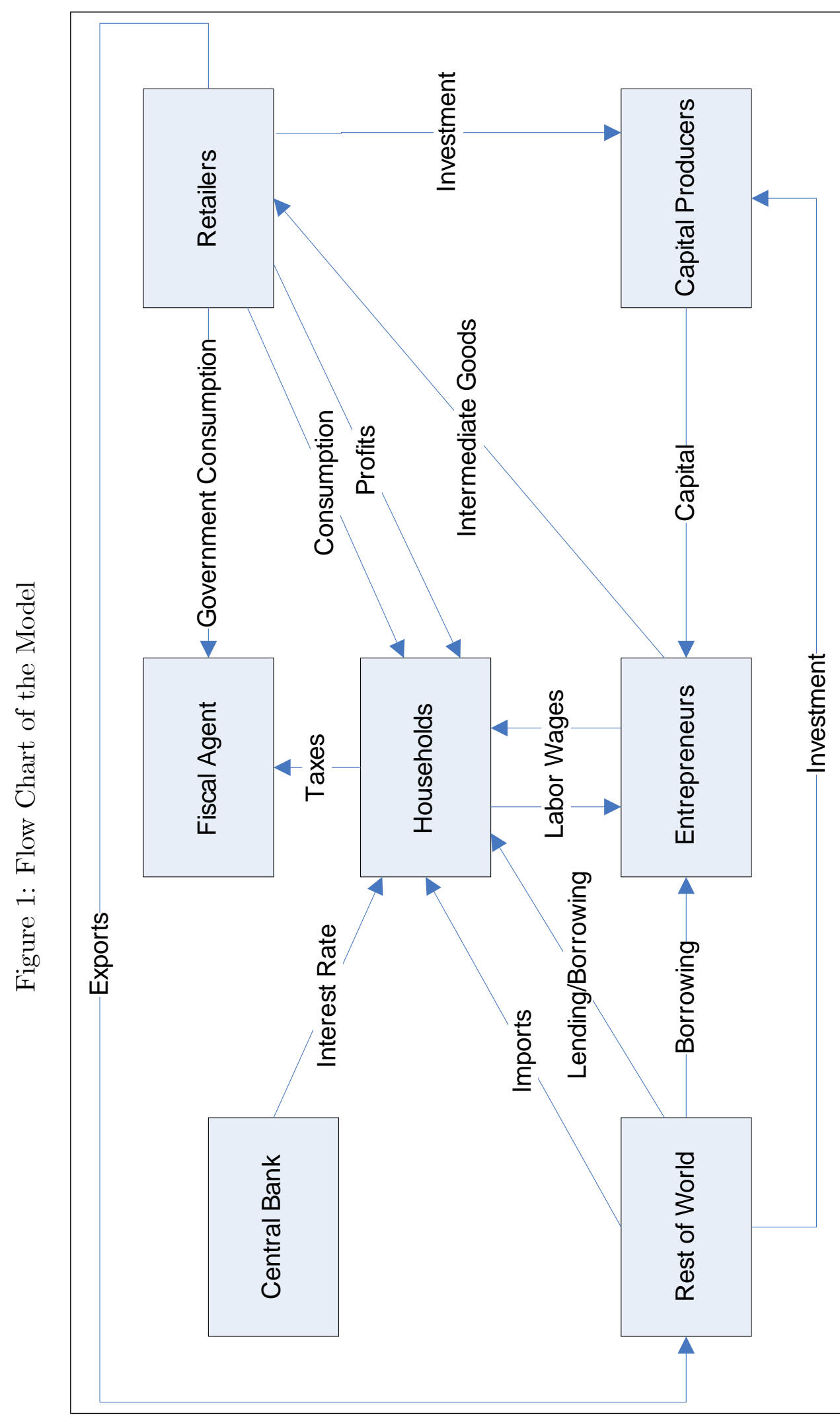


The basic structure of model consists of four kinds of agents - households, entrepreneurs, capital producers and retailers. Households consume a composite of domestic and imported goods and provide labor. They have access to foreign capital markets and make deposits which are used by entrepreneurs to purchase capital. Entrepreneurs produce intermediate goods using labor and capital purchased from capital producers. They finance the acquisition of capital partly through their net worth and partly through borrowing domestically and abroad. Entrepreneurs produce intermediate goods under perfect competition and sell their product to retailers who differentiate them at no cost and sell them either in domestic market or export overseas. Retailers operate in a monopolistically competitive environment and face a quadratic adjustment costs in changing prices à la Rotemberg (1982). Capital producers use a combination of the existing capital stock and investment goods purchased from retailers and abroad to produce capital. The markets for capital, labor and domestic loans are competitive. The model is completed with a description of the fiscal and monetary authority. Our model differs from BGG in its characterization of monetary policy using a modified Taylor-type rule. We assume that the Reserve Bank of India adjusts shortterm interest rates in response to inflation, output, and nominal exchange rate changes.

In order to provide a rationale for monetary stabilization policy, three sources of inefficiency are included in the model: (a) monopolistically competitive retail markets; (b) sluggish price adjustment in retail sector; (c) capital adjustment costs. While relatively simple, the framework captures many of the rigidities which previous studies have found are important to describe the dynamics in the data and serves as a useful starting point for developing a DSGE model for India.

\subsection{Household}

The economy is populated with a continuum of infinitely lived households with preferences defined over consumption, $C_{t}(j)$, and labor effort, $L_{t}(j)$. The objective of household $j$ is to maximize the expected value of a discounted sum of period utility functions:

$$
E_{0} \sum_{t=0}^{\infty} \beta^{t} U\left(C_{t}(j), L_{t}(j)\right)
$$


$\beta \in(0,1)$ is the consumer subjective discount factor and $U$ is a period utility function. We include habit persistence according to the specification:

$$
U\left(C_{t}(j), L_{t}(j)\right)=\zeta_{c, t}(1-b) \ln \left(C_{t}(j)-b C_{t-1}\right)-\frac{\zeta_{L, t}}{\psi} L_{t}(j)^{\psi}
$$

where $C_{t-1}$ is lagged aggregate consumption and $b \in(0,1) . \quad \zeta_{c, t}$ and $\zeta_{L, t}$ are preference shocks to the marginal utility of consumption and the supply of labour, respectively. Note that in symmetric steady-state where $C_{t}(j)=$ $C_{t-1}$, the marginal utility of consumption is independent of the habit persistence parameter $b$. The aggregate consumption bundle, $C_{t}(j)$, consists of domestically produced goods, $C_{H, t}$, and an imported foreign good, $C_{F, t}$, and is given by:

$$
C_{t}(j) \equiv\left[\alpha^{\frac{1}{\eta}}\left(C_{H, t}(j)\right)^{\frac{\eta-1}{\eta}}+(1-\alpha)^{\frac{1}{\eta}}\left(C_{F, t}(j)\right)^{\frac{\eta-1}{\eta}}\right]^{\frac{\eta}{\eta-1}}
$$

where $C_{H, t}$ is an index of consumption of domestic goods given by the constant elasticity of substitution (CES) function:

$$
C_{H, t}(j)=\left(\int_{0}^{1} C_{H, t}(s)^{\frac{\varepsilon_{t}-1}{\varepsilon_{t}}} d s\right)^{\frac{\varepsilon_{t}}{\varepsilon_{t}-1}}
$$

where $s \in[0,1]$ denotes the variety of the domestic good. The parameter $\eta \in[0, \infty]$ is the elasticity of substitution between domestic and foreign goods. The parameter $\varepsilon_{t}>1$ is the elasticity of substitution between varieties produced within the country, while $\alpha \in[0,1]$ can be interpreted as a measure of home-bias.

We assume that households have access to foreign financial markets or nominal contingent claims that span all relevant household specific uncertainty about future income and prices, interest rates, exchange rates and so on. As a result each household faces a single intertemporal budget constraint:

$$
\begin{aligned}
P_{t} C_{t}(j)+e_{t} B_{t+1}(j)+P_{t} \tau_{t}+P_{t} d_{t}(j)= & e_{t} B_{t}(j)\left(1+i_{t-1}^{f}\right)+ \\
& \int_{0}^{1} \pi_{t}(s) d s+W_{t} L_{t}(j) \\
& +\left(1+i_{t-1}\right) P_{t} d_{t-1}(j)
\end{aligned}
$$


where $B_{t}$ is net holdings of a foreign currency one-period bond that matures in period $t$ paying an interest rate of $i_{t-1}^{f}$. Households make a deposit $d_{t}$ with a financial intermediary, which earns an interest of $i_{t} \cdot \int_{0}^{1} \pi_{t}(s) d s$ represents receipts of the profits from domestic retailers owned by the household in the economy. $\tau_{t}$ is the lump sum tax in the economy and $W_{t}$ is the nominal wage rate per unit of labor. ${ }^{1} P_{t}$ is the CPI price index given by:

$$
P_{t} \equiv\left[\alpha\left(P_{H, t}\right)^{1-\eta}+(1-\alpha)\left(P_{F, t}\right)^{1-\eta}\right]^{\frac{1}{1-\eta}}
$$

where $P_{H, t}$ is the domestic price index given by:

$$
P_{H, t}=\left[\int_{0}^{1_{t}} P_{H, t}(s)^{1-\varepsilon_{t}} d s\right]^{1 /\left(1-\varepsilon_{t}\right)}
$$

and $P_{F, t}$ is the price of imported goods. ${ }^{2}$

Households choose the paths of $\left\{C_{t}(j), L_{t}(j), d_{t}(j), B_{t+1}(j)\right\}_{t=0}^{\infty}$ to maximize expected lifetime utility (1) subject to the constraint (5) and the initial value of $B_{0}$. The consumer's problem can therefore be written as:

$$
\max _{C_{t}, d_{t}, B_{t+1}, L_{t}} E_{t} \sum_{t=0}^{\infty} \beta^{t}\left\{-\lambda_{t}\left[\begin{array}{c}
U\left(C_{t}(j), L_{t}(j)\right) \\
e_{t} B_{t+1}(j)- \\
e_{t} B_{t}(j)\left(1+i_{t-1}^{f}\right)+P_{t} d_{t} \\
-\left(1+i_{t-1}\right) P_{t} d_{t-1} \\
+P_{t} \tau_{t}-W_{t} L_{t}(j)- \\
\int_{0}^{1} \pi_{t}(s) d s+P_{t} C_{t}(j)
\end{array}\right]\right\}
$$

Ruling out Ponzi type schemes, we get the following first order conditions:

$$
\begin{gathered}
\frac{(1-b) \zeta_{c, t}}{C_{t}(j)-b C_{t-1}}=\lambda_{t} P_{t} \\
\zeta_{L, t} L_{t}(j)^{\psi-1}=\lambda_{t} W_{t}
\end{gathered}
$$

\footnotetext{
${ }^{1}$ The only role of the financial intermediary in this model is to channel the deposits of households to enterpreneurs.

${ }^{2}$ We assume that the price of imported goods are set in the same manner as the domestic prices in the exporting country i.e. the price of imports adjust sluggishly and is given by an equation similar to equation 40 .
} 
Given the well documented departures from uncovered interest parity (UIP), we follow Kollman (2002) and introduce an exogenous shock into the consumers first-order condition for foreign currency bond holdings. The firstorder conditions for deposits and foreign currency bond holdings are therefore given by:

$$
\begin{aligned}
1 & =\left(1+i_{t}\right) E_{t}\left\{\rho_{t, t+1} \frac{P_{t}}{P_{t+1}}\right\} \\
1 & =\left(1+i_{t}^{f}\right) E_{t}\left\{\rho_{t, t+1} \frac{P_{t}}{P_{t+1}} \frac{e_{t+1}}{e_{t}}\right\}
\end{aligned}
$$

where $\rho_{t, t+1}=\beta \frac{\lambda_{t}}{\lambda_{t+1}}=\frac{\zeta_{c, t}\left(C_{t+1}(j)-b C_{t}\right)}{\zeta_{c, t+1}\left(C_{t}(j)-b C_{t-1}\right)}$ is the stochastic discount factor. Up to a log-linear approximation equations (11) and (12) imply $E_{t} \ln \left(e_{t+1} / e_{t}\right) \approx$ $i_{t}-i_{t}^{f}$. The optimum allocation of expenditure between domestic and imported goods is given by

$$
\begin{aligned}
C_{H, t}(j) & =\alpha\left(\frac{P_{H, t}}{P_{t}}\right)^{-\eta} C_{t}(j) \\
C_{F, t}(j) & =(1-\alpha)\left(\frac{P_{F, t}}{P_{t}}\right)^{-\eta} C_{t}(j)
\end{aligned}
$$

and the demand for each variety of domestic goods is given by:

$$
C_{H, t}(s)=\left(\frac{P_{H, t}(s)}{P_{t}}\right)^{-\varepsilon_{t}} C_{H, t}(j)
$$

For simplicity, we assume that changes in the exchange rate are passed through immediately to the import price so that $P_{F, t}=u_{t}^{\text {tot }} \frac{\varepsilon_{t}}{\left(\varepsilon_{t}-1\right)} e_{t} P_{t}^{*}$ where $u_{t}^{\text {tot }}$ is a shock to the terms of trade of the economy.

\subsection{Production Sector}

\subsubsection{Entrepreneurs}

We model the behavior of entrepreneurs as proposed by BGG . We follow the modeling framework of Gertler, Gilchrist, and Natalucci (2007) and Elekdag, Justiniano, and Tchakarov (2005) while introducing a financial accelerator in an open economy context. Entrepreneurs combine labor, hired from households, and capital, purchased from capital producers, to produce intermediate 
goods in a perfectly competitive setting. They are risk neutral and have a finite horizon for planning purposes. The probability that an entrepreneur will survive until the next period is $\nu$, so the expected live horizon is $\frac{1}{1-\nu}{ }^{3}$ The number of new entrepreneurs entering the market each period is equal to the number of entrepreneurs exiting, implying a stationary population. To get started, new entrepreneurs receive a small transfer of funds from exiting entrepreneurs.

At the end of each period $t$, entrepreneurs purchase capital $k_{t+1}$, to be used in the subsequent period at a price $q_{t}$. They finance capital acquisition partly by their net worth available at the end of period $t, n_{t+1}$, and partly by borrowing domestically and by raising foreign currency denominated debt. Total borrowing, $B_{t}$, is given by:

$$
B_{t}=q_{t} K_{t+1}-n_{t+1}
$$

where $q_{t}$ is the real price per unit of capital. The fraction of loan raised domestically, $B_{t}^{d}$, is exogenous to the model and is given by $\varpi$. Thus,

$$
B_{t}^{d}=\varpi B_{t}=\varpi\left(q_{t} K_{t+1}-n_{t+1}\right)
$$

and

$$
\left.B_{t}^{f}=(1-\varpi)\left(q_{t-1} K_{t}-n_{t}\right)\right)
$$

where $B_{t}^{f}$, is the amount of loan raised from abroad. Entrepreneurs use $K_{t}$ units of capital and $L_{t}$ units of labor to produce output, $Y_{t}^{W}$, using a constant returns to scale technology:

$$
Y_{t}^{W} \leq \theta_{t} K_{t}^{\psi} L_{t}^{1-\psi}, \quad \psi \in(0,1)
$$

where $\theta_{t}$ is a stochastic disturbance to total factor productivity. The entrepreneur maximizes profit by choosing $K_{t}$ and $L_{t}$ subject to the production function given by equation (19). The first order conditions for this optimization problem are:

$$
W_{t}=(1-\psi) P_{H, t}^{W} \frac{Y_{t}^{W}}{L_{t}}
$$

\footnotetext{
${ }^{3}$ This assumption ensures that entrepreneur's net worth (the firm equity) will never be enough to fully finance the new capital acquisition.
} 


$$
r_{k t}=\frac{P_{H, t}^{W}}{P_{t}}(1-\psi) \frac{Y_{t}^{W}}{K_{t}}
$$

where $P_{H, t}^{W}$ is the price of the wholesale good. ${ }^{4}$ The expected marginal real return on capital acquired at $t$ and used at $t+1$ yields the expected gross return $E_{t}\left(1+r_{t+1}^{k}\right)$, where

$$
E_{t}\left(1+r_{t+1}^{k}\right)=E_{t}\left[\frac{r_{k t+1}+(1-\delta) q_{t+1}}{q_{t}}\right]
$$

and $\delta$ is the rate of depreciation of capital and $r_{k t+1}$ is the marginal productivity of capital at $t+1$.

Following BGG, we assume that there exists an agency problem which makes external finance more expensive than internal funds. While entrepreneurs costlessly observe their output, which is subject to random outcomes, lenders cannot verify output outcomes of entrepreneurs costlessly. After observing the outcome, entrepreneurs decide whether to repay their debt or to default. If they default, lenders audit the loan and recover the outcome less monitoring costs. This agency problem makes loans riskier and thus lenders charge a premium over the risk free rate. Thus, entrepreneurs' marginal external financing cost is the product of the gross premium and the gross real opportunity cost of funds (the riskless interest rate) that would arise in the absence of capital market frictions.

Therefore, the expected marginal cost of borrowing, $E_{t} f_{t+1}$, is given by:

$$
\begin{aligned}
& E_{t} f_{t+1}=\Theta\left(\frac{n_{t+1}}{q_{t} K_{t+1}}\right) E_{t}\left[\frac{\left(1+i_{t}\right)}{\pi_{t+1}}\right]+\Theta\left(\frac{n_{t+1}}{q_{t} K_{t+1}}\right) E_{t}\left[\frac{\left(1+i_{t}^{f}\right)}{\pi_{t+1}^{*}} \frac{R E R_{t+1}}{R E R_{t}}\right] \\
& \Theta^{\prime}<0 \text { and } \Theta(1)=1
\end{aligned}
$$

where $\Theta$ is the gross finance premium which depends on the size of the borrower's equity stake in a project (or, alternatively, the borrower's leverage ratio). $\pi_{t}=\frac{P_{t}}{P_{t-1}}$, is the gross domestic inflation, $\pi_{t}^{*}=\frac{P_{t}^{*}}{P_{t-1}^{*}}$, is the gross world inflation and $R E R_{t}$ is the real exchange rate defined as: ${ }^{5}$

$$
R E R_{t}=\frac{e_{t} P_{t}^{*}}{P_{t}}
$$

\footnotetext{
${ }^{4}$ Since the firms are perfectly competitive this is equivalent to saying that $P_{H, t}^{W}=M C_{t}^{W}$.

${ }^{5}$ We have assumed that law of one price holds for all differentiated goods.
} 
We characterize the risk premium, $\Theta$ by $\left(\frac{n_{t+1}}{q_{t} K_{t+1}}\right)^{\sigma}$, where $\sigma$ represents the elasticity of the external finance premium with respect to a change in the leverage position of entrepreneurs. As $\frac{n_{t+1}}{q_{t} K_{t+1}}$ falls, the entrepreneur relies on uncollateralized borrowing (higher leverage) to a larger extent to fund his project. Since this increases the incentive to misreport the outcome of the project, the loan becomes riskier and the cost of borrowing rises. ${ }^{6}$ Entrepreneurs demand for capital depends on the expected marginal return and the expected marginal cost of borrowing. Thus, the entrepreneur's demand for capital satisfies the following optimality condition:

$$
\begin{aligned}
E_{t}\left(1+r_{t+1}^{k}\right)= & \Theta\left(\frac{n_{t+1}}{q_{t} K_{t+1}}\right) E_{t}\left[\frac{\left(1+i_{t}\right)}{\pi_{t+1}}\right] \\
& +\Theta\left(\frac{n_{t+1}}{q_{t} K_{t+1}}\right) E_{t}\left[\frac{\left(1+i_{t}^{f}\right)}{\pi_{t+1}^{*}} \frac{R E R_{t+1}}{R E R_{t}}\right]
\end{aligned}
$$

Equation (25) provides the foundation for the financial accelerator. It links entrepreneurs' financial position to the marginal cost of funds and, hence, to the demand for capital. Also, movements in the price of capital , $q_{t}$, may have significant effects on the leverage ratio. In this way the model captures the link between asset price movements and collateral stressed in the Kiyotaki and Moore (1997) theory of credit cycles. ${ }^{7}$ At the beginning of each period, entrepreneurs collect their returns from capital and honor their debt obligations. Aggregate entrepreneurial net worth evolves according to:

$$
n_{t+1}=\nu V_{t}+(1-\nu) G_{t}
$$

where $V_{t}$ is the net worth of the surviving entrepreneurs carried over from the previous period, $1-\nu$ is the share of new entrepreneurs entering and $G_{t}$

\footnotetext{
${ }^{6}$ When the riskiness of loans increases, the agency costs rise and the lender's expected losses increase. A higher external finance premium paid by successful entrepreneurs offsets these higher losses and ensures that there is no change to the return on deposits for households.

${ }^{7}$ Though the behavior described above is true for an individual entrepreneur, we appeal to the assumptions in BGG that permit us to write it as an aggregate condition. See BGG and Carlstrom and Fuerst (1997) for details. It implies that gross finance premium may be expressed as a function of the aggregate leverage ratio, i.e. it is not entrepreneur specific.
} 
(which is exogenous in the model) are the transfers from exiting to newly entering entrepreneurs. $V_{t}$ is given by:

$$
V_{t}=\left[\begin{array}{c}
\left(1+r_{t}^{k}\right) q_{t-1} K_{t}-\Theta\left(\frac{n_{t}}{q_{t-1} K_{t}}\right)\left[\frac{\left(1+i_{t-1}\right)}{\pi_{t}}\right]\left(\varpi\left(q_{t-1} K_{t}-n_{t}\right)\right) \\
\left.-\Theta\left(\frac{n_{t}}{q_{t-1} K_{t}}\right)\left[\frac{\left(1+i_{t-1}^{f}\right)}{\pi_{t}^{*}} \frac{R E R_{t}}{R E R_{t-1}}\right](1-\varpi)\left(q_{t-1} K_{t}-n_{t}\right)\right)
\end{array}\right]
$$

As equations (27) and (28) suggest, the principal source of movements in net worth stems from unanticipated movements in returns and borrowing costs. In this regard, unforecastable variations in asset prices, $q_{t}$, is the main source of fluctuations in $\left(1+r_{t}^{k}\right)$. On the cost side, unexpected movements in inflation and exchange rates are the major sources of fluctuations in net worth. An unexpected deflation or depreciation, for example, reduces entrepreneurial net worth, thus enhancing the financial accelerator mechanism. Entrepreneurs going out of business at time $t$ consume and transfer some funds to new entrepreneurs out of the residual equity $(1-\nu) V_{t}$. Thus the consumption by the entrepreneurs is given by:

$$
C_{t}^{e}=(1-\nu)\left(V_{t}-G_{t}\right)
$$

\subsubsection{Capital Producers}

Capital producers combine the existing capital stock, $K_{t}$, leased from the entrepreneurs to transform an input $I_{t}$, gross investment, into new capital $K_{t+1}$ using a linear technology. ${ }^{8}$ The aggregate capital stock evolves according to:

$$
K_{t+1}=(1-\delta) K_{t}+\zeta_{I, t} I_{t}-\left(\frac{\kappa}{2}\left(\frac{I_{t}}{K_{t}}-\delta\right)^{2}\right) K_{t}
$$

where $\zeta_{I, t}$ is a shock to the marginal efficiency of investment (as in Greenwood, Hercowitx, and Hauffman, 1988).

Gross investment consists of domestic and foreign final goods and we assume that it is in the same proportion as in the consumption basket:

$$
I_{t} \equiv\left[\alpha^{\frac{1}{\eta}}\left(I_{H, t}\right)^{\frac{\eta-1}{\eta}}+(1-\alpha)^{\frac{1}{\eta}}\left(I_{F, t}\right)^{\frac{\eta-1}{\eta}}\right]^{\frac{\eta}{\eta-1}}
$$

\footnotetext{
${ }^{8}$ This setup follows Bernanke et al. (1999) and assumes that capital producers rent the capital stock from entrepreneurs and use it to produce new capital. Since this takes place within the period we assume that the rental rate is zero.
} 
Optimal demand for domestic and imported investment is therefore given by:

$$
\begin{aligned}
I_{H, t} & =\alpha\left(\frac{P_{H, t}}{P_{t}}\right)^{-\eta} I_{t} \\
I_{F, t} & =\alpha\left(\frac{P_{F, t}}{P_{t}}\right)^{-\eta} I_{t}
\end{aligned}
$$

and the price of investment is the same as the domestic price index given by equation (6).

We assume that capital producers face a quadratic capital adjustment costs specified as $\left(\frac{\kappa}{2}\left(\frac{I_{t}}{K_{t}}-\delta\right)^{2}\right) K_{t}$. Capital producing firms maximize expected profits:

$$
\underset{I_{t}}{\operatorname{Max} E_{t}}\left\{q_{t}\left[\zeta_{I, t} I_{t}-\left(\frac{\kappa}{2}\left(\frac{I_{t}}{K_{t}}-\delta\right)^{2}\right) K_{t}\right]-I_{t}\right\}
$$

and the corresponding first order condition for the supply of capital is given by:

$$
q_{t}\left[\zeta_{I, t}-\kappa\left(\frac{I_{t}}{K_{t}}-\delta\right)\right]=1
$$

\subsubsection{Retailers}

There is a continuum of retailers $s \in[0,1]$. They purchase wholesale goods at a price equal to the nominal marginal costs, $M C_{t}^{W}$ (the marginal cost in the entrepreneurs' sector) and differentiate them at no cost. ${ }^{9}$ Then they sell their product in a monopolistically competitive domestic and export market. Final good domestic output, $Y_{H, t}$, is the CES composite of individual retail goods:

$$
Y_{H, t}=\left(\int_{0}^{1} Y_{H, t}(s)^{\frac{\varepsilon_{t}-1}{\varepsilon_{t}}} d s\right)^{\frac{\varepsilon_{t}}{\varepsilon_{t}-1}}
$$

\footnotetext{
${ }^{9}$ The entreprenuers sell their goods in a perfectly competitive market, so $P_{t}^{W}=M C_{t}^{W}$. The retail sector is used only to introduce nominal rigidity into the economy. Since they differentiate goods costlessly, the marginal cost of producing final goods is same as $M C_{t}^{W}$.
} 
The corresponding price of the composite consumption good, $P_{H, t}$, is given by equation (7). Using equation (36), the demand curve facing each retailer can be written as:

$$
Y_{H, t}(s)=\left(\frac{P_{H, t}(s)}{P_{t}}\right)^{-\varepsilon_{t}} Y_{H, t}
$$

For simplicity we assume that the aggregate export demand function: $Q_{t}^{x}=$ $\left[P_{X, t} / P_{t}^{*}\right]^{-\eta_{t}}, \quad \eta_{t}>0$.

Price Setting by Retailers Following Ireland (2001) and Rotemberg (1982), there is sluggish price adjustment to make the intermediate goods pricing decision dynamic. This ensures that monetary policy has real effects on the economy. Following, Julliard, Karam, Laxton, and Pesenti (2004) we assume that the retailers face an explicit cost of price adjustment measured in terms of the intermediate goods given by:

$$
\frac{\vartheta}{2}\left[\frac{P_{d, t}(s) / P_{d, t-1}(s)}{\Pi}-1\right]^{2}\left(Q_{t}^{d}+Q_{t}^{x}\right)
$$

where $\vartheta \succeq 0$ is the parameter determining the cost of price adjustment relative to last period's price level and the steady state domestic inflation, $\Pi$, respectively. Following Saxegaard (2006b), real profits are given by:

$$
\begin{aligned}
\pi_{t}\left[P_{H, t}(s), P_{X, t}(s)\right]= & {\left[\frac{P_{H, t}(s)}{P_{t}}-\frac{M C_{t}^{W}}{P_{t}}\right]\left[\frac{P_{H, t}(s)}{P_{H, t}}\right]^{-\varepsilon_{t}} Q_{t}^{d} } \\
& +\left[\frac{e_{t} P_{X, t}(s)}{P_{t}}-\frac{M C_{t}^{W}}{P_{t}}\right]\left[\frac{P_{X, t}(s)}{P_{X, t}}\right]^{-\varepsilon_{t}} Q_{t}^{x} \\
& -\frac{\vartheta}{2}\left[\frac{P_{H, t}(s) / P_{H, t-1}(s)}{\Pi}-1\right]^{2}\left(Q_{t}^{d}+Q_{t}^{x}\right)
\end{aligned}
$$

where $Q_{t}^{d}$ is the total domestic demand and $Q_{t}^{x}$ is the total exports. $e_{t}$ is the nominal exchange rate, expressed as the domestic currency price of foreign currency, so that an increase in $e_{t}$ implies a depreciation of the domestic currency. Note also that we allow for a shock to the elasticity of substitution between differentiated goods $\varepsilon_{t}$, which determines the size of the markup of intermediate goods firms. Alternatively, the shock to $\varepsilon_{t}$ can be interpreted as a cost-push shock of the kind introduced into the New Keynesian model by Clarida, Gali, and Gertler (1999). 
The optimal price setting equation for the non-tradable price can then be written as:

$$
\begin{aligned}
P_{H, t}=\frac{\varepsilon_{t}}{\left(\varepsilon_{t}-1\right)} M C_{t}^{W} & -\frac{\vartheta}{\left(\varepsilon_{t}-1\right)} P_{t} \frac{\Pi_{H, t}}{\Pi}\left[\frac{\Pi_{H, t}}{\Pi}-1\right] \\
& +\frac{\vartheta}{\left(\varepsilon_{t}-1\right)} P_{t} E_{t}\left\{\rho_{t, t+1} \frac{Y_{H, t+1}}{Y_{H, t}} \frac{\Pi_{H, t+1}}{\Pi}\left[\frac{\Pi_{H, t+1}}{\Pi}-1\right]\right\}
\end{aligned}
$$

where we have used the fact that all retailer firms are alike to impose symmetry and where we assume that the law of one price holds in the export market so that $P_{X, t}=P_{H, t} / e_{t}$. Equation (40) reduces to the well-known result that prices are set as a markup over marginal costs if the cost of price adjustment $\vartheta=0$. In general however, the goods price will follow a dynamic process and the firm's actual markup will differ from, but gravitate towards, the desired markup. Profits from retail activity are rebated lump-sum to households (i.e. households are the ultimate owners of retail outlets).

\subsection{The Government}

The fiscal authority is assumed to purchase an exogenous stream $G_{t}$ of the final good which is financed by the collection of lump-sum taxes. ${ }^{10}$ For simplicity, we do not assume that the fiscal authority has access to domestic or international capital markets. Its period-by-period budget constraint is given by:

$$
G_{t}=\tau_{t}
$$

Government buys both domestic and foreign final goods and we assume that it is in the same proportion as the consumers:

$$
G_{t} \equiv\left[\alpha^{\frac{1}{\eta}}\left(G_{H, t}\right)^{\frac{\eta-1}{\eta}}+(1-\alpha)^{\frac{1}{\eta}}\left(G_{F, t}\right)^{\frac{\eta-1}{\eta}}\right]^{\frac{\eta}{\eta-1}}
$$

Optimum demand for government domestic and imported consumption is given by:

\footnotetext{
${ }^{10} \mathrm{We}$ assume for simplicity that government only consumes domestic goods.
} 


$$
\begin{aligned}
G_{H, t} & =\alpha\left(\frac{P_{H, t}}{P_{t}}\right)^{-\eta} G_{t} \\
G_{F, t} & =\alpha\left(\frac{P_{F, t}}{P_{t}}\right)^{-\eta} G_{t}
\end{aligned}
$$

In choosing a specification for the monetary policy reaction function, we assume a simple Taylor rule type function given by:

$$
i_{t}=\rho_{i}\left(i_{t-1}\right)+\left(1-\rho_{i}\right) \bar{i}+\rho_{\pi}\left(\pi_{t}-\bar{\pi}\right)+\rho_{Y}\left(Y_{t}-\bar{Y}\right)+\rho_{q}\left(q_{t}-\bar{q}\right)+\zeta_{i, t}
$$

where $\rho_{\pi}, \rho_{Y}$ and $\rho_{q}$ are the weights on inflation, output and the depreciation rate of the nominal exchange rate. Parameter $\rho_{i}$ captures interest rate smoothing, and where $\bar{\imath}$ is the steady state interest rate. $\zeta_{i, t}$, is a monetary policy shock to capture unanticipated increase in the nominal interest rate. Equation (45) is essentially a simple Taylor rule with partial adjustment. We interpret this rule as being a form of flexible inflation targeting in the sense of Bernanke and Mishkin (1997).

\subsection{Market Clearing and Aggregation}

Domestic households, exiting entrepreneurs, capital producers, and government, and the rest of the world buy final goods from retailers. The economywide resource constraint is therefore given by: ${ }^{11}$

$$
Y_{H, t}=C_{H, t}+C_{H, t}^{e}+I_{H, t}+G_{H, t}+Q_{t}^{x}=Q_{t}^{d}+Q_{t}^{x}
$$

where:

$$
Q_{t}^{d}=C_{H, t}+C_{H, t}^{e}+I_{H, t}+G_{H, t}
$$

and $Q_{t}^{x}$ is the quantity exported and $G_{H, t}$, is the Government's demand of domestically produced goods. The national accounting equation is given by:

$P_{t} * Z Z_{t}=P_{t}\left(C_{t}+C_{t}^{e}+I_{t}+G_{t}\right)+P_{X, t} Q_{t}^{x}-P_{M, t} Q_{t}^{m}+\frac{\vartheta}{2}\left[\frac{P_{H, t}(s)}{\Pi_{P_{H, t-1}(s)}}-1\right]^{2} P_{H, t} Y_{H, t}$

\footnotetext{
${ }^{11}$ Following Bernanke et al. (1999), we ignore monitoring costs in the general equilibrium.
} 
where $Q_{t}^{m}$ is total imports and $Z Z_{t}$ is real GDP. ${ }^{12}$

The model allows for non-zero holdings of foreign currency bonds by households and foreign currency denominated debt by entrepreneurs. In particular, it is well known (see inter alia Schmitt-Grohe and Uribe (2003)) that unless adjustments are made to the standard model, the steady state of an small open-economy model with foreign currency bonds will depend upon initial conditions and will display dynamics with random walk properties. In particular, if the domestic discount rate exceeds the real rate of return on foreign currency bonds, then domestic holdings of foreign currency bonds will increase perpetually. Beyond the obvious conceptual problems of such an outcome our analysis is constrained by the fact that the available techniques used to solve non-linear business cycle models of the type considered here are only valid locally around a stationary path.

Fortunately, a number of modifications to the standard model are available which enable us to overcome this issue. In this paper, we follow SchmittGrohe and Uribe (2003) and specify a foreign debt elastic risk-premium whereby holders of foreign debt are assumed to face an interest rate that is increasing in the country's net foreign debt. In particular, $i_{t}^{f}$, the interest rate at which households and entrepreneurs can borrow foreign currency equals the exogenous world interest rate plus a spread that is a decreasing function of economy's net foreign asset position:

$$
\left(1+i_{t}^{f}\right)=\left(1+i_{t}^{*}\right)-\chi_{d}\left[\left(\left(B_{t}+L_{t}^{f}\right) / P_{t}^{*}-\vartheta_{t}\right)-\left(\left(B+L^{f}\right) / P^{*}-\vartheta\right)\right] / \Omega, \quad \chi_{d} \succ 0
$$

where $\chi_{d}$ is a parameter which captures the degree of capital mobility in the market for foreign-currency borrowing and lending by households and $\Omega$ is the steady-state value of exports. As in Schmitt-Grohe and Uribe (2003) we include the steady-state level of debt so that the risk-premium is nil in steady state. Note that under perfect capital mobility $\left(\chi_{d}=0\right)$, the country would face an infinite supply or demand of foreign capital and the model would not have a well-defined steady state. As Kollmann (2002) points out, the model in this case becomes a version of the permanent income theory of consumption, with non-stationary consumption and net assets.

\footnotetext{
${ }^{12}$ Real GDP can alternatively be written as $(1-\alpha)\left(\frac{P_{F, t}}{P_{t}}\right)^{-\eta}\left(C_{t}+C_{t}^{e}+I_{t}+G_{t}\right)$.
} 


\subsection{Specification of the Stochastic Processes}

We include a number of shocks in order to ensure that the model is not stochastically singular and in order to be better able to reproduce the dynamics in the data. In particular, the number of exogenous shocks must be at least as large as the number of observed variables in order to estimate the model using classical Maximum Likelihood or Bayesian methods. Our model includes thirteen structural shocks: three shocks to technology and preferences $\left(\theta_{t}\right.$, $\left.\zeta_{c, t}, \zeta_{l, t}\right)$, three foreign shocks to world interest rates, world inflation, and the price elasticity of exports $\left(i_{t}^{*}, \Pi_{t}^{*}, Q_{t}^{x}\right)$, two shocks to investment efficiency and firms' markup $\left(\zeta_{i n, t}, \zeta_{v, t}\right)$, two financial shocks to the cost of borrowing by entrepreneurs and the survival rate of entrepreneurs $\left(\zeta_{n, t}, \zeta_{v, t}\right)$, a monetary policy shock, a government spending shock $\left(\zeta_{i, t}, \zeta_{G, t}\right)$, and a UIP shock $\left(\zeta_{\text {uip }, t}\right)$. With the exception of the monetary policy shock, which is assumed to be a white noise processes, all shocks are assumed to follow a first-order autoregressive process. ${ }^{13}$

\section{Data and Estimation Strategy}

We estimate the model using the Bayesian estimation module in DYNARE Juillard (2001). Bayesian inference has a number of benefits. First, it formalizes the use of prior empirical or theoretical knowledge about the parameters of interest. Second, Bayesian inference provides a natural framework for parameterizing and evaluating simple macroeconomic models that are likely to be fundamentally mis-specified. Thus, as pointed out by Fernandez-Villaverde and Rubio-Ramirez (2004) and Schorfheide (2000), the inference problem is not to determine whether the model is 'true' or the 'true' value of a particular parameter, but rather to determine which set of parameter values maximize the ability of the model to summarize the regular features of the data. Finally, Bayesian inference provides a simple method for comparing and choosing between different mis-specified models that may not be nested on the basis of the marginal likelihood or the posterior probability of the model. In particular, Geweke (1998) shows that the marginal likelihood is directly related to the predictive performance of the model which provides a

\footnotetext{
${ }^{13}$ In addition to our thirtheen structural shocks, we follow the approach adopted in Julliard, Karam, Laxton, and Pesenti (2004) of allowing for measurement errors in the data.
} 
natural benchmark for assessing the usefulness of economic models for policy analysis and forecasting.

Bayesian estimation requires construction of the posterior density of the parameters of interest given the data. If we denote the set of parameters to be estimated as $\theta$ using observations on a set of variables $X$, the posterior density can be written as $p(\theta \mid X)$. The posterior density is thus the probability distribution of $\theta$, conditional on having observed the data $X$. It forms the basis for inference in the Bayesian framework. Following Bayes law, the posterior density is proportional to the product of the prior density of the parameters $p(\theta)$ and the distribution of the data given the parameter set $f(X \mid \theta)$ :

$$
p(\theta \mid X)=\frac{p(\theta) f(X \mid \theta)}{f(X)}
$$

where $f(X)$ is the marginal distribution of the data. The conditional distribution function of the data given the parameter set $f(X \mid \theta)$ is equivalent to the likelihood function of the set of parameters given the data $L(\theta \mid X)$. The likelihood function can be calculated from the state-space representation of the model using the Kalman filter (see Ljungqvist and Sargent (2004) for details). Bayesian inference therefore requires (i) the choice of prior densities for the parameters of interest, and (ii) construction of the posterior from the prior densities and the likelihood function. The remainder of this section discusses briefly how to construct the posterior distribution. The choice of prior is discussed later, together with the estimation results.

Given the likelihood function and a set of prior distributions, an approximation to the posterior mode of the parameters of interest can be calculated using a Laplace approximation. The posterior mode obtained in this way is used as the starting value for the Metropolis-Hastings algorithm (see Bauwens, Lubrano, and Richard (1999) for details). This algorithm allows us to generate draws from the posterior density $p(\theta \mid X)$. At each iteration, a proposal density (a normal distribution with mean equal to the previously accepted draw) is used to generate a new draw which is accepted as a draw from the posterior density $p(\theta \mid X)$ with probability $p$. The probability $p$ depends on the value of the posterior and the proposal density at the candidate draw, relative to the previously accepted draw. We generate 100000 draws in 4 chains in this manner, discarding the first 50000 draws to reduce the importance of the starting values. 


\subsection{Data}

To estimate the model we use information on ten key macroeconomic variables for India running from 1996Q2 to 2007Q4: GDP, private consumption expenditure, investment, exports, imports (all expressed in constant prices), the real exchange rate, the rate of depreciation of the nominal exchange rate, wholesale price inflation, the nominal interest rate, and the Bombay Stock Exchange SENSEX Index. ${ }^{14}$ The 3 -month Treasury Bill rate is used as a proxy of the nominal interest rate and the real effective exchange rate calculated by the IMF is used as proxy for the real exchange rate. As in Christiano, Motto, and Rostagno (2007) we use the value of the stock exchange index (deflated using the wholesale price index) to proxy the net worth of entrepreneurs. All variables are expressed as deviations from a Hodrick-Prescott time trend and, with the exception of the real and nominal exchange rates, the nominal interest rate, and the SENSEX, are seasonally adjusted using the X12 filter. All data are taken from the CEIC database.

\subsection{Calibration of Steady-State Parameters}

As in Saxegaard (2006a), we calibrate the parameters in the model that determine the steady state based on findings from previous studies and the data. We then estimate the parameters that determine the dynamic properties of the model away from the steady-state. The list of calibrated parameters include the rate of time preference, $\beta$, the depreciation rate of capital, $\delta$, the cost share of capital, $\psi$, the price elasticity of aggregate non-tradables and imports, $\eta$, the price elasticity of exports, $\varsigma$, the share of non-tradables in the WPI, $\alpha$, the steady-state markup for retailers, $\varepsilon /(\varepsilon-1)$, in addition to several steady-state ratios which are set so as to replicate the average in the data. The calibrated parameter values and the implied steady-state ratios are summarized in table 1.

The substitution elasticity between imported and domestically produced goods is set at 1.5, close to the value used by Saxegaard (2006a) for the Philippines, while the elasticity of substitution of exports, $\varsigma$, was set to 2.4 , a value consistent with the steady-state export to GDP ratio. With the share of non-tradables in the WPI, $\alpha$, set at 0.8 , this corresponds to a steady-state export to GDP ratio of 19 percent and a steady-state import to GDP ratio

\footnotetext{
${ }^{14}$ More recent data is not included given the increased volatility associated with the global financial crisis.
} 
Table 1: Calibrated Parameters

\begin{tabular}{ccl}
\hline Parameter & Value & Description \\
\hline$\eta$ & 1.5 & Price elasticity of non-tradables and imports \\
$\varsigma$ & 2.4 & Price elasticity of exports \\
$\alpha^{d}, 1-\alpha^{m}$ & 0.8 & Share of non-tradables in CPI \\
$v /(v-1)$ & 1.09 & Steady state markup factor for intermediary goods \\
$\psi$ & 0.33 & Cost share of capital \\
$\delta$ & 0.025 & Quarterly depreciation rate of capital \\
$\Pi$ & $1.045^{1 / 4}$ & Steady state inflation \\
$1+i$ & $1.07^{1 / 4}$ & Steady state domestic interest rate \\
$\Pi^{*}$ & $1.025^{1 / 4}$ & Steady state inflation \\
$s_{g}$ & 0.27 & Steady state government absorption \\
\hline
\end{tabular}

of 21 percent. The share of government expenditure in GDP is set at 11 percent as in the data. The steady-state markup factor is set to 9 percent so that $\varepsilon=12$. The technology parameter $\psi$ is set at 0.33 which is consistent with much of the literature. As in much of the literature, the depreciation rate is set at 10 percent per annum, implying a value of $\delta$ of 0.025 .

We set the steady-state annual nominal interest rate at 7 percent which corresponds to the annualized average quarterly rate for the period we have data on. Similarly, steady-state inflation was set equal to 4.5 percent which corresponds to the average seasonally adjusted quarterly WPI inflation over the period on an annualized basis. Intertemporal optimization by consumers implies that the subjective discount rate, $\beta$, is set equal to 0.994 which is the inverse of the quarterly real steady-state interest rate. We set world inflation equal to 2.5 percent on an annual basis which implies a steady-state depreciation rate of the nominal exchange rate of 2 percent on an annual basis and a world interest rate of 5 percent per annum.

\subsection{Prior Distribution of Estimated Parameters}

Our choice of prior distributions for the estimated parameters is guided both by theoretical considerations and empirical evidence. Given the lack of significant empirical evidence, however, we choose relatively diffuse priors that cover a wide range of parameter values. For the structural parameters, we choose either gamma distributions or beta distributions in the case when a parameter - such as the autoregressive shock processes - is restricted by 
theoretical considerations to lie between zero and one. Given the lack of evidence regarding the policy reaction function of the Reserve Bank of India, we use uniform distributions for the parameters of the monetary policy rule. Finally, as in much of the literature the inverted gamma distribution is used for the standard errors of the shock processes. This distribution guarantees a positive variance but with a large domain. The choice of priors for the parameters to be estimated is summarized in table 2 .

As mentioned previously, we assume that firms incur a quadratic cost of price adjustment, measured in terms of current inflation, relative to the previous periods inflation rate. We use the gamma distribution to restrict the adjustment cost parameters $\left(\vartheta_{d}, \vartheta_{x}\right)$ to the positive manifold and, given the lack of evidence on the degree of nominal rigidity in emerging markets, specify a mean of 100 with a standard deviation of 20. As noted by Gali and Gertler (1999) an adjustment cost of 100 corresponds approximately to the assumption that firms change prices (or inflation) every 3.74 quarters. There is considerable uncertainty surrounding the appropriate value of the capital cost adjustment cost parameter $(\Phi)$ in the model. While Kollmann (2002) finds a value of 1.43 in their model, Ireland (2001) and Ireland (2003) find values above 30 . The mean of the prior on the capital adjustment cost parameter $(\Phi)$ is set at 15 (as in Kollmann (2002)) with a gamma distribution.

Our choice of prior distributions for the parameters of the monetary policy reaction function is based on the fact that there is little evidence regarding the Reserve Bank of India's interest rate setting behavior. ${ }^{15}$ As a result, we choose uniform priors for the feedback parameters on inflation, output, and the rate of exchange rate depreciation in the policy rule with a relatively large domain. In particular, we choose uniform prior distributions with a minimum of 0 and a maximum of 3 for the feedback parameter on WPI inflation $\left(\rho_{\pi}\right)$ and the rate of exchange rate depreciation $\left(\rho_{q}\right)$. This encompasses the estimates found by Mohanty and Klau (2004). For the feedback parameter on the output gap $\left(\rho_{y}\right)$, we choose a uniform distribution with a minimum of -1 and a maximum of 1 . This is consistent with the finding in Mohanty and Klau (2004) that several emerging market central banks do not base their policy response on movements in the output gap in a systematic fashion. The lagged interest rate prior $\left(\rho_{i}\right)$ follows a beta distribution with

\footnotetext{
${ }^{15}$ A notable exception is Mohanty and Klau (2004) who finds that the parameters of the monetary policy reaction function in India are much lower than in other countries in Asia. A more detailed comparison between their results and ours is done in the next section.
} 
mean 0.7 and standard deviation of 0.2 . This is consistent with the estimate in Mohanty and Klau (2004).

The prior on the habit persistence parameter $(b)$ is assumed to follow a beta distribution to ensure that it remains bounded between 0 and 1 . We assume a mean of 0.5 and a standard deviation of 0.2 for the prior distribution. The mean of our prior is lower than the values used inter alia by Julliard, Karam, Laxton, and Pesenti (2004) and Smets and Wouters (2003) reflecting the assumption that a higher share of consumers in India is likely to be cash-constrained and thus unable to smooth consumption. However, the relatively large standard deviation implies that the prior distribution is relatively diffuse and covers a broad range of estimates.

As in Dib, Mendicino, and Zhang (2008), we choose a prior with a gamma distribution for the elasticity of the external finance premium. We assume a mean of 0.07 which is consistent with previous findings in the literature (see inter alia (Elekdag, Justiniano, and Tchakarov 2005), (Christensen and Dib 2006), and (Dib, Mendicino, and Zhang 2008)) and a standard deviation of 0.02. For the risk premium on foreign-currency borrowing $\left(\chi_{d}\right)$ we use a gamma distribution with a mean of 0.0019, as in Saxegaard (2006a), and a standard error of 0.002 .

Finally, for the priors of the autoregressive parameters and the standard errors of the stochastic processes, we follow the same procedure as in Smets and Wouters (2005) and Julliard, Karam, Laxton, and Pesenti (2004). The persistence parameters are given a prior with a beta distribution to restrict the domain between 0 and 1 . The mean of the distribution for each of the autoregressive parameters is set at 0.8. For the standard errors, we use the inverted gamma distribution with a diffuse prior. The inverted gamma distribution is commonly used for standard errors as it gives support to all positive values of the parameter and has characteristics which ease the computational burden of the estimation processes. In order to specify the precise mean of the prior distribution for the standard errors of the structural shocks, we have relied on the variance decomposition of the model. In other words, we experimented with different sized shocks until we arrived at a specification which entailed a reasonable contribution of each of the structural shocks to the total variability of our observed variables. This approach was preferred to relying on previous studies given that the importance of shocks cannot be directly inferred from the size of their standard errors due to normalization 
issues. ${ }^{16}$ In any case, the use of a diffuse prior reduces the importance of the mean of the prior distribution on the outcome of the estimation.

\section{Empirical Results}

Table 2 reports the estimated posterior model together with the 90 percentile of the posterior distribution. Figure 2 provides a visual representation of this information by plotting the prior and posterior distribution for each parameter that is estimated, together with the posterior mode. These plots allow us to make some statements about the relative importance of the prior and the data in the construction of the posterior distribution. Overall, our model yields plausible parameter estimates for the parameters of the model which are broadly in line with results from previous studies.

The estimate of the elasticity of the external finance premium with respect to firm leverage $\sigma$ is equal to 0.057 . This is slightly below the estimate of 0.066 for Korea in Elekdag, Justiniano, and Tchakarov (2005) and somewhat higher than estimate in Dib, Mendicino, and Zhang (2008) using Canadian data. The investment adjustment cost parameter $\Phi$ is estimated at 23.0, significantly higher than the prior mean. As pointed out by Christensen and Dib (2006), capital adjustment costs have an important interaction with the financial accelerator. If capital adjustment costs are high, the price of capital will tend to be more volatile. As net worth responds directly to the price of capital (through capital gains and losses), it affects the external finance premium faced by corporates, leading to increased investment volatility.

The habit persistence parameter $(b)$ is estimated at 0.499 , implying that there are significant delays in the effect of interest rate changes on aggregate expenditure, and consumption in particular. As we expected, these estimates are somewhat lower than found in other studies including Saxegaard (2006a) and Smets and Wouters (2005) given the higher share of cash-constrained consumers in India. With regards to the cost of price adjustment, our estimates suggest that domestic prices are more sluggish relatively to what is typically found in the literature. Moreover, the plots of the posterior in figure 2 suggest that the data is quite informative about this parameter. Our estimate of the cost of adjusting import prices, however, is close to the prior, which is not surprising given that we do not include data on import prices in our sample.

\footnotetext{
${ }^{16}$ See Lubik and Schorfheide (2005) for details.
} 
With regards to the estimates of the policy rule parameters, our results indicate that the Reserve Bank of India places a relatively high weight on controlling the rate of depreciation of nominal exchange rate. In particular the estimate of $\gamma_{e}$, the coefficient that measures the response of monetary policy to exchange rate movements, is 3 times higher than $\gamma_{\Pi}$, the coefficient on inflation. Moreover, the results suggest that output stabilization does not play a significant part in the conduct of monetary policy, with the estimate of $\gamma_{Y}$ insignificantly different from zero. Because the model is estimated in levels, a simple transformation is necessary to be able to interpret these numbers. In particular, they imply that annual nominal interest rate increase by 0.9 percentage points if annual inflation is 1 percentage point above its equilibrium value. Similarly, annual interest rates increase by 1 percentage point if the nominal exchange rate depreciates by 1 percent more than the equilibrium rate of depreciation. Interestingly, these estimates are significantly higher than the estimates found by Mohanty and Klau (2004) in their study of the monetary policy reaction function for India. Their results suggest a 0.13 percentage point increase in annual interest rates if annual inflation increases by 1 percentage point, while a 0.18 percentage point increase in annual interest rates if the real exchange rate depreciations by 1 percent. While the fact that Mohanty and Klau (2004) is a partial equilibrium study means that their results are not directly comparable to ours, it is noteworthy that they also find a relatively strong response to movements in the exchange rate in India.

Finally, our estimates of the shock processes suggest that the shock to the markup and the price elasticity of exports are the most persistent stochastic processes. The persistence of the shock to uncovered interest parity suggests that departures from uncovered interest parity are pervasive in the data. Our estimates of the standard errors of the structural shocks are also reported in 5 . However, as pointed out by Lubik and Schorfheide (2005), the interpretation of these is not straightforward and is dependent on the scale of the variables.

\subsection{Cross-validation with alternative models}

As suggested by Christensen and Dib (2006) we compare the fit of our model, the Estimated FA model, against an alternative model without a financial accelerator. The alternative model, which we call the Estimated No-FA model, is identical to the FA model with the exception that the parameter that captures the elasticity of the external finance premium with respect 
Figure 2: Prior and Posterior Distributions
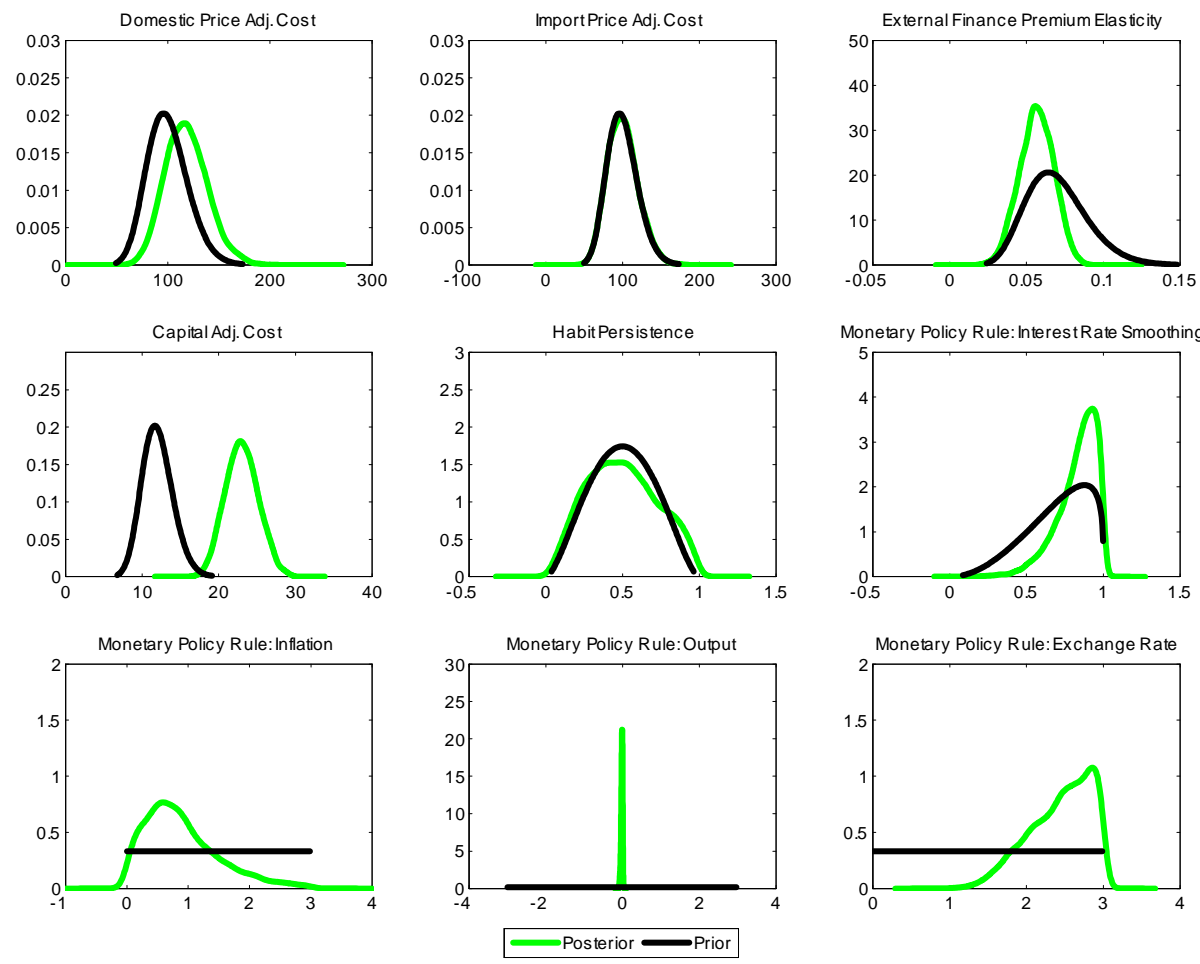
to firm leverage is constrained to equal zero. In addition, as suggested by Schorfheide (2000), we compare the fit our estimated model against a less restrictive non-structural reduced form Bayesian vector autogression (BVAR) estimated using the popular Litterman prior (Sims and Zha 1998). This provides a stringent test of the ability of our model to replicate the dynamics in the data and thus of its usefulness as a tool for policy analysis. Indeed, it is partly evidence suggesting that empirical DSGE models with a sufficient number of structural shocks compare favorably with BVARs which has prompted the increased interest in DSGE models in policy making. ${ }^{17}$

Bayesian econometrics provides a natural framework for assessing the empirical performance of different mis-specified models. Using Bayes Law again we can write the posterior probability of a model $M_{i}$ as:

$$
p\left(M_{i} \mid X\right)=\frac{p\left(M_{i}\right) L\left(M_{i} \mid X\right)}{f(X)}
$$

where $p\left(M_{i}\right)$ is the prior belief attached to model $i$ and $L\left(M_{i} \mid X\right)$ is the likelihood of the model given the data. Bayesian model selection is based on the posterior odds ratio of a particular model $M_{1}$ against another model $M_{2}$ which is given by:

$$
\frac{p\left(M_{1} \mid X\right)}{p\left(M_{2} \mid X\right)}=\frac{p\left(M_{1}\right) L\left(M_{1} \mid X\right)}{p\left(M_{2}\right) L\left(M_{2} \mid X\right)}
$$

where $\frac{L\left(M_{1} \mid X\right)}{L\left(M_{2} \mid X\right)}$-the ratio of marginal likelihoods for different models-represents a summary measure of the evidence provided by the data for choosing between two competing models.

Table 2 reports the marginal likelihood of the Estimated FA model, the Estimated No-FA model, and BVARs estimated on the same data set at lags 1 to 4 . The higher marginal likelihood in the Estimated FA model relative to the Estimated No-FA Model suggests that the introduction of a financial accelerator mechanism does improve the model's ability to capture the movements observed in the data. As in Elekdag, Justiniano, and Tchakarov (2005), however, the Estimated FA model does not compare favorably to a BVAR with one lag although it dominates BVARs with more lags. This is not surprising as the marginal likelihood falls with increasing model complexity and increases with model fit. The improved fit of our Estimated FA model relative to a BVAR with one lag does not compensate for its higher

\footnotetext{
${ }^{17}$ See inter alia Smets and Wouters (2005), Julliard, Karam, Laxton, and Pesenti (2004), and Lubik and Schorfheide (2005).
} 
Table 2: Model Comparison

\begin{tabular}{lc}
\hline & Marginal Likelihood \\
\hline Estimated FA model & 876.49 \\
Estimated No-FA model & 873.64 \\
BVAR $(1)$ & 1148.54 \\
BVAR $(2)$ & 420.19 \\
BVAR $(3)$ & 673.25 \\
BVAR $(4)$ & 743.61 \\
\hline
\end{tabular}

complexity. Nevertheless, the fact that the Estimated FA model outperforms BVARs with more than one lag does provide some evidence in support of the Estimated FA model as a tool of policy analysis.

\subsection{Impulse Responses}

A useful way to illustrate the dynamics of the estimated model and the importance of the financial accelerator is to consider the impulse response functions when the financial accelerator is present and when it is not. The response of some key macroeconomic variables to a 100 bps increase in the nominal interest rate are shown in figure 3, to a positive technology shock in figure 4, and to a shock to borrowing costs in figure 5. Each variable's response is expressed as the percentage deviation from its steady-state level, with the exception of the rate variables, which are in percentage points. In figures 3 to 5 the impulse responses generated in the estimated FA model are shown in black. The impulse responses generated when the financial accelerator is not present are shown in green. As in Christensen and Dib (2006), we generate these impulse responses by setting the elasticity of the external finance premium with respect to firm leverage equal to zero, but keeping all the other parameter estimates from the estimated FA model. The difference between the black and the green lines should give an indication of the impact of the financial accelerator on a particular variable after a given shock.

Figure 3 shows that the presence of a financial accelerator amplifies and propagates the impact of a contractionary monetary policy shock. In both models, the increase in the nominal interest rate raises the cost of domestic borrowing for consumers and thus leads to a contraction in consumption. It also raises the demand for domestic bonds and thus appreciates the domes- 
Figure 3: The Economy's Response to a 100 Bps Contractionary Monetary Policy Shock

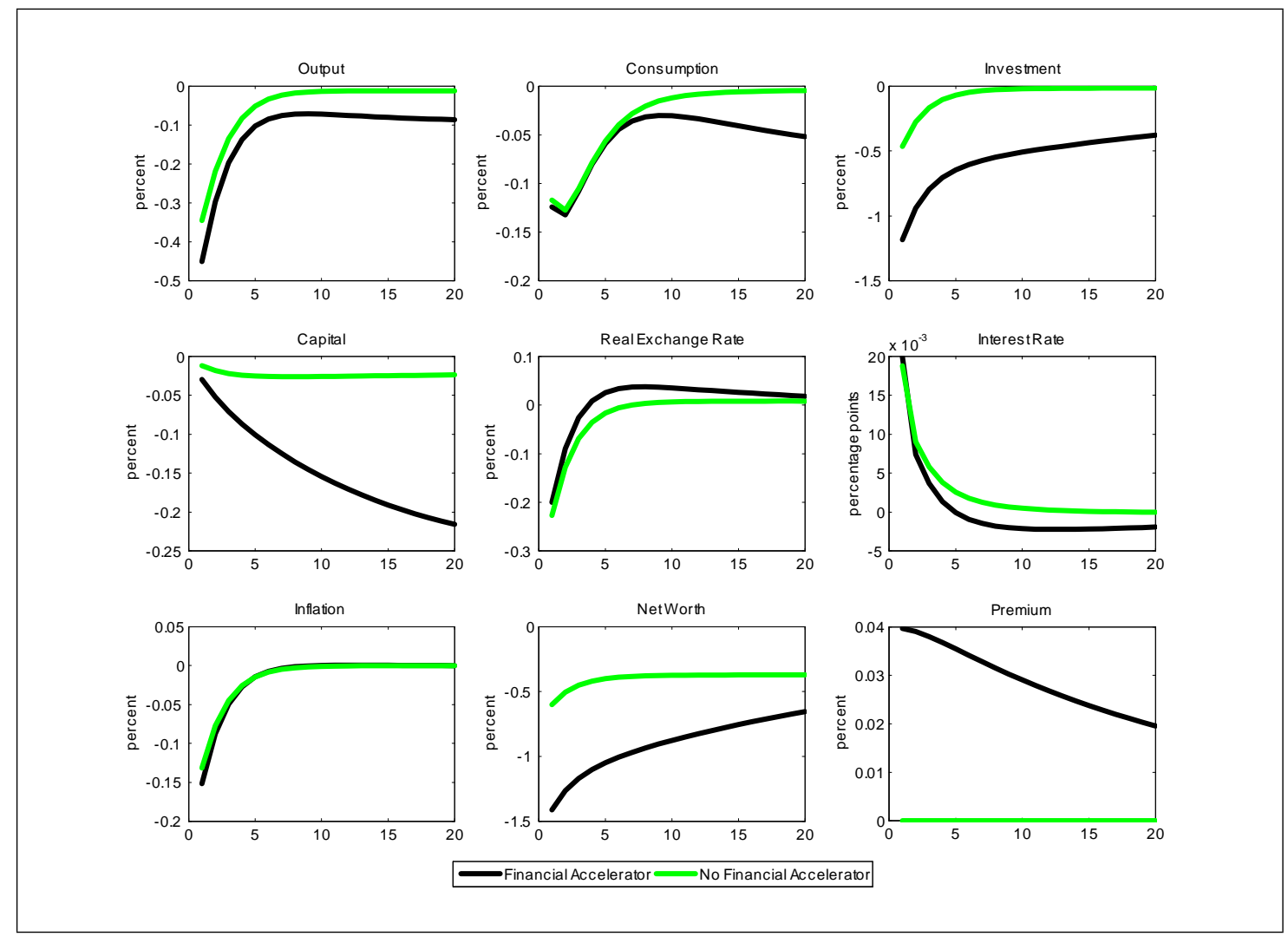


tic currency, while the net worth of entrepreneurs declines because of the declining return to capital and higher real interest costs associated with existing debt (the debt-deflation effect). Output contracts both as a result of decreased domestic demand and a result of decreased competitiveness following the appreciation of the real exchange rate. The contraction in demand in turn leads to a fall in inflation. In the presence of the financial accelerator, the external finance premium increases as a result of the decline in net worth and rising leverage. This pushes up the real borrowing cost for entrepreneurs, putting downward pressure on investment and the price of capital which further reduces net worth. This reduction in net worth leads to a further increase in the cost of borrowing (the premium goes up), thus reducing capital, investment and output further (second round effects). This mechanism amplifies the magnitude and the persistence of transitory monetary policy shocks as evident from the impulse responses.

Figure 4 shows that the financial accelerator has less of an impact following a positive shock to technology. The technology shock increases the return to capital and thus leads to an increase in investment and output. At the same time, the improvement in technology reduces firms' marginal costs and thus reduces inflation. The higher return to capital and lower inflation have opposite effects on net worth but in our model the positive impact of the higher return to capital dominates. This is partly due to the endogenous response of monetary policy which pushes up nominal interest rates, thereby reducing the amount of deflation. When the financial accelerator is active, the rise in net worth pushes down the risk premium faced by entrepreneurs and leads to a larger response of investment and capital. While output is somewhat more volatile when the financial accelerator is present, the impact if significantly less than following a shock to monetary policy.

Figure 5 also shows that the financial accelerator amplifies the effects of a financial shock such as a shock to the borrowing costs faced by entrepreneurs. In both models, the higher borrowing costs depresses the demand for new capital and thus lowers investment, output, and inflation. The decline in absorption, in turn, reduces the demand for non-tradables and causes a real exchange rate depreciation. The exchange rate depreciation (which raises the external borrowing cost of entrepreneurs), together with the decline in inflation, reduces entrepreneurs' net worth. In the presence of the financial accelerator, this increases the entrepreneurs' risk premium and reduces the demand for capital further. As a result, the decline in investment and output is much larger when the financial accelerator is present. 
Figure 4: The Economy's Response to a 1 Percent Improvement in Technology
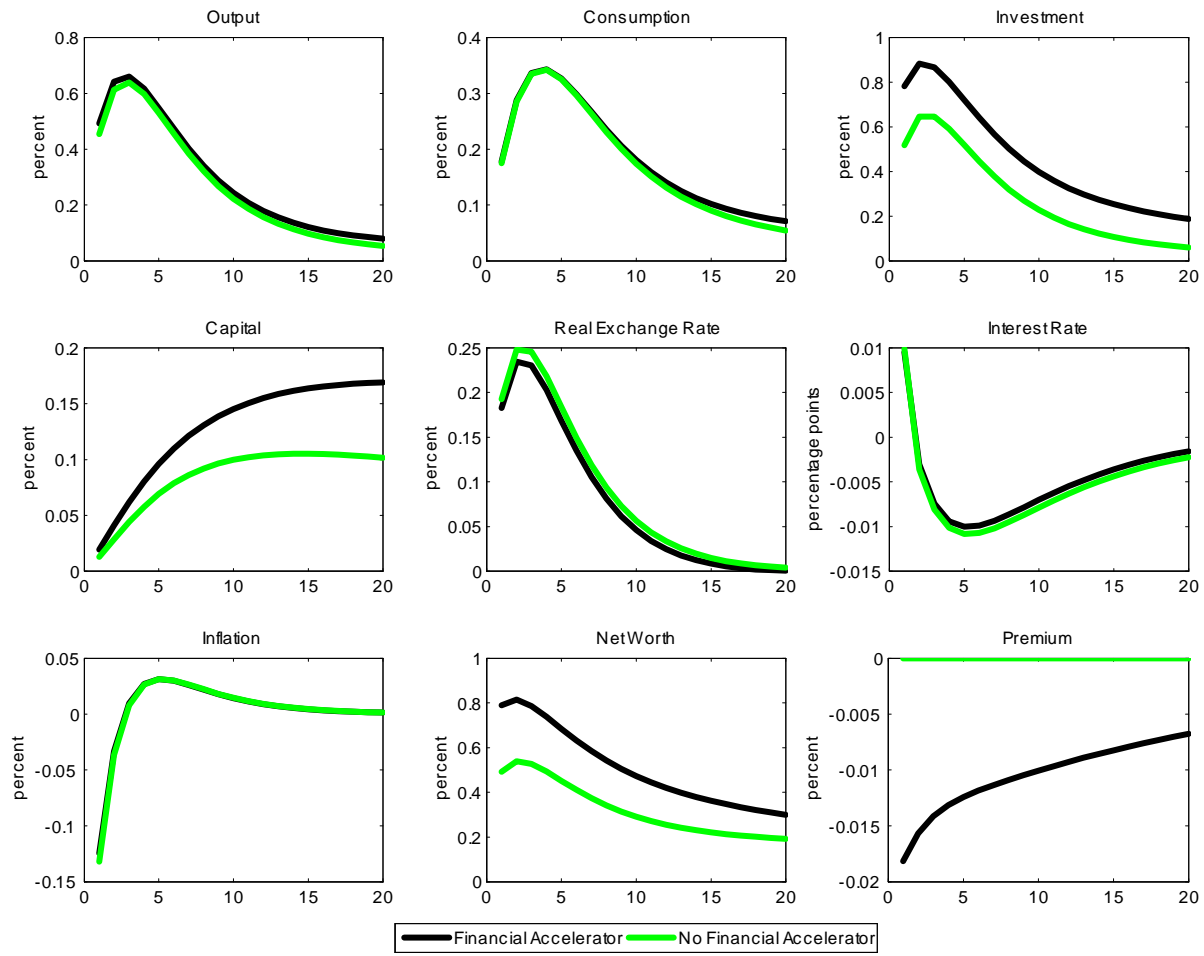
Figure 5: The Economy's Response to a 1 Percent Increase in Enterpreneur's Borrowing Cost

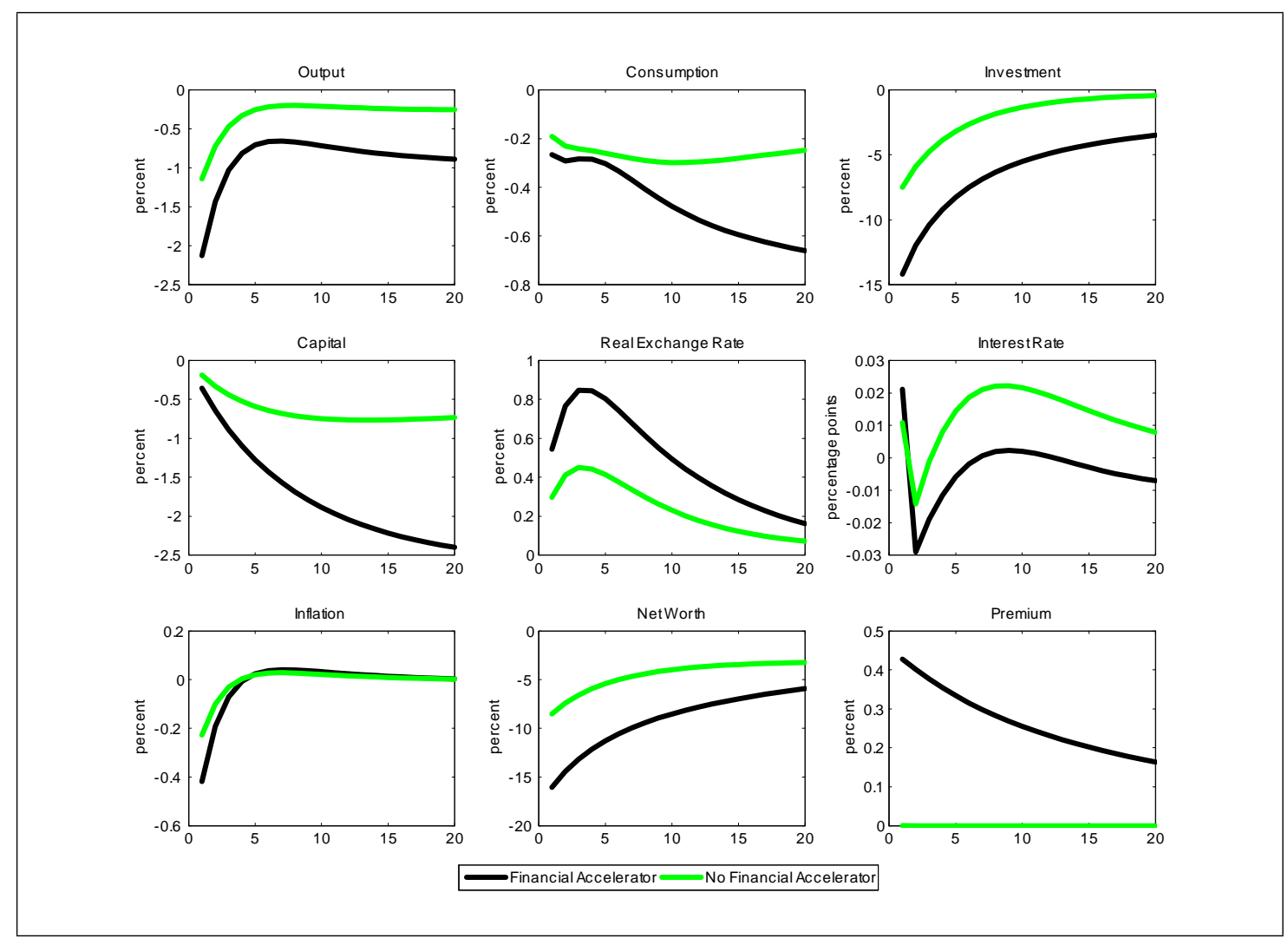


Table 3: Parameters of an Optimal Policy Rule

\begin{tabular}{lllll}
\hline & $\rho_{i}$ & $\rho_{\pi}$ & $\rho_{Y}$ & $\rho_{q}$ \\
\hline Estimated Policy Rule & 0.83 & 0.89 & 0.02 & 2.44 \\
Optimal Policy Rule & 0.995 & 5.75 & 0.00 & 1.05 \\
\hline
\end{tabular}

As in previous studies, therefore, the financial accelerator amplifies and propagates the impact of shocks on investment. The impact of the financial accelerator on other variables including output and inflation depends, however, on the type of shock. Following a contractionary monetary policy shock and a shock to entrepreneurs' cost of borrowing, output and inflation volatility increases when the financial accelerator is present. The financial accelerator has much less of an impact, however, on the economy following a shock to technology. This is consistent with the results in other studies including Christensen and Dib (2006).

\section{Optimal Policy}

How does the estimated monetary policy rule compare to an policy rule which maximizes consumer welfare? To answer this question we search for the parameters of the monetary policy reaction function in equation 45 that maximizes a second-order approximation of consumer welfare. ${ }^{18}$ The results of this exercise are presented in table 3 , while the volatility implied by the different rules and the resulting consumer welfare is presented in table 4.

The parameters of a policy rule that maximizes welfare differs significantly from the parameters of the estimated policy rule. Our results suggest that the estimated policy rule places too little emphasis on inflation stabilization and too much emphasis on stabilizing the rate of depreciation of the nominal exchange rate. The lower than optimal weight on inflation stabilization in the estimated policy rule, coupled with a significantly higher than optimal weight

\footnotetext{
${ }^{18}$ In the non-stochastic flexible-price equilibrium or steady-state, monetary policy is neutral in the sense that all the monetary rules we consider imply the same non-stochastic steady-state for the economy. Furthermore, given that up to a first-order (Taylor series) approximation consumer welfare is equal to its non-stochastic steady-state value, changes in the monetary policy regime will only have second-order (or higher) effects on welfare. As a result, we follow the majority of the literature in approximating welfare using a secondorder Taylor series approximation to expected utility. This method leads to a loss-function similar to that widely assumed in the earlier literature on monetary policy evaluation.
} 
on exchange rate stabilization, suggests that the RBI places more emphasis on stabilizing the rate of depreciation than on reducing inflation volatility. As a result, inflation volatility is higher under the estimated policy rule than under the optimal rule, while exchange rate volatility is lower. Both the estimated rule and the optimal rule feature significant interest-rate inertia, which implies that the authorities react to inflation much more aggressively in the long run than in the short run. ${ }^{19}$ At the same, time the emphasis on stabilizing the rate of depreciation of the nominal exchange rate in the estimated policy rule comes at the expense of higher volatility in the real economy (despite the fact that the weight on output stabilization is broadly similar in both rules), while the volatility of financial sector variables-in particular borrowing costs and net worth-is also higher.

We calculate a second-order accurate measure of consumer welfare associated with different monetary policy regimes as in Schmitt-Grohe and Uribe (2004). In particular, we calculate the expectation of lifetime utility as of time zero, $V_{0}$, associated with a particular monetary regime, denoted with the superscript, $r$ :

$$
V_{0}^{r} \equiv E_{0} \sum_{t=0}^{\infty} \beta^{t} U\left(C_{t}^{r}, L_{t}^{r}\right)
$$

conditional on the economy being at its non-stochastic steady-state at time zero.

In order to evaluate the cost of the estimated monetary policy rule relative to the welfare optimizing rule, we follow Schmitt-Grohe and Uribe (2004) and calculate the fraction of a consumer's consumption that would make them indifferent between different regimes. ${ }^{20}$ In particular, $\lambda$ is defined as the fraction of the household's consumption under the optimal policy rule that consumers would have to give up to be as well off under the empirical policy rule as under the optimal policy rule so that a value of $\lambda * 100=1$ represents one percent of permanent consumption. Formally $\lambda$ is defined as:

$$
V_{0}^{e s t}=E_{0} \sum_{t=0}^{\infty} \beta^{t} U\left[(1-\lambda) C_{t}^{o p t}, L_{t}^{o p t}\right]
$$

\footnotetext{
${ }^{19}$ Interest rate interia is in fact somewhat higher in the optimal rule reflecting possibly the impact interest rate volatility has on the volatility of net worth and thus the real economy.

${ }^{20}$ It is fairly common in the literature to only look at the implementable rules rather than truely optimal "Ramsey allocation" that can not be implemented. This is the approach we follow in this paper.
} 
where $V_{0}^{e s t}$ denotes the expectation of lifetime utility as of time zero under the estimated policy rule while $C_{t}^{o p t}$ and $L_{t}^{o p t}$ refer to the amount of labour and consumption under the optimal rule. For the particular functional form in our model this implies:

$$
\lambda=1-e^{\left[\frac{1-\beta}{\zeta_{c, t}(1-b)}\left(V_{0}^{e s t}-V_{0}^{o p t}\right)\right]}
$$

where $V_{0}^{\text {opt }}$ denotes the expectation of lifetime utility as of time zero under the optimal policy rule. From table 4 we see that the welfare loss under the sub-optimal estimated policy rule is equivalent to a not insignificant 0.4 percent of permanent consumption. ${ }^{21}$ This is close to the welfare gain found by Kollmann (2002) but lower than that found by Ambler, Dib, and Rebei (2004).

It is useful to compare our results to those in Schmitt-Grohe and Uribe (2007) who calculate welfare maximizing policy rules using a closed-economy model calibrated using U.S. data and to those in Leith, Moldovan, and Rossi (2009) who analyze the welfare maximizing policy rule under different degrees of habit persistence. We also compare our results to those in Ambler, Dib, and Rebei (2004) who look at an open-economy model estimated using Canadian and U.S. data, although their results are not directly comparable to ours given the inclusion of money growth in the policy rule and the absence of interest rate smoothing. Both Leith, Moldovan, and Rossi (2009) and Schmitt-Grohe and Uribe (2007) find that a significant degree of interest rate smoothing-albeit less than in our model-is optimal and contributes to substantially lower macroeconomic volatility. Leith, Moldovan, and Rossi (2009) and Schmitt-Grohe and Uribe (2007) also find that a high weight on inflation stabilization, and a zero weight on output stabilization is optimal. Schmitt-Grohe and Uribe (2007) restrict the weight on inflation stabilization to be less than 3 on the grounds that higher values may not be implementable. However, they note than in the absence of such a restriction the optimal weight is 332. Similarly, Leith, Moldovan, and Rossi (2009) find that an estimate around 30 is optimal for the amount of habit persistence we estimate in our model. Ambler, Dib, and Rebei (2004) on the other hand, find a much lower optimal weight on inflation (1.2) and a higher weight on output stabilization (0.2).

\footnotetext{
${ }^{21}$ In other words, consumption in every period over the life-time of a consumer would be 0.4 percent lower under the estimated rule than under the optimal rule.
} 


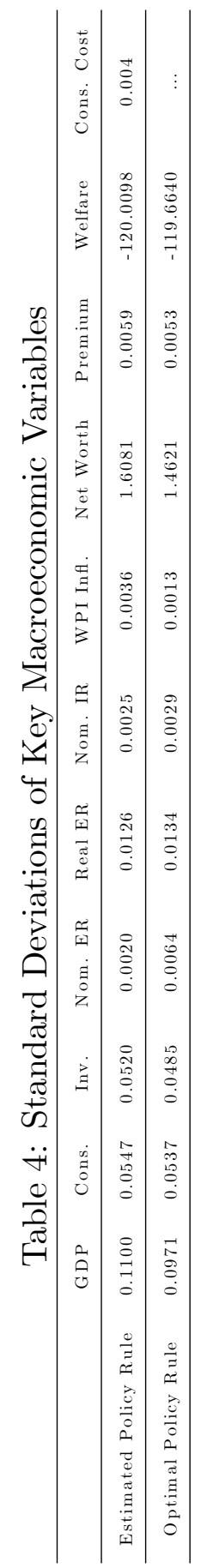


Figure 6 illustrates our results by simulating the path of output, inflation, the rate of depreciation of the nominal exchange rate, and the nominal interest rate under the estimated policy rule and the optimal policy rule, using the estimated path of the stochastic shocks in the model. These plots confirm that inflation volatility would have been lower if monetary policy had been conducted according to the optimal policy rule. This was particularly true toward the end of 2004 (WPI inflation increased to 8.1 percent y.o.y. in the third quarter of 2004) and in 2006/07. At the same the rate of depreciation of the nominal exchange rate displays a significantly higher amount of volatility during the whole sample period under the optimal rule. Finally, the simulation of the nominal interest rate suggest that interest rates would have been higher toward the end of the sample-given the relatively high inflation-if monetary policy had been conducted according to the optimal policy rule.

\section{Concluding Remarks}

The aim of this paper has been to estimate a DSGE model with macrofinancial linkages for India and to use it to analyze the conduct of monetary policy. The DSGE model used is an extension of the model developed in Saxegaard (2006b) augmented to include a financial accelerator mechanism similar to that proposed by BGG to study the effect of financial frictions on the real economy.

As is increasingly common in this literature, the model was estimated using Bayesian estimation techniques. Bayesian estimation techniques provide a natural framework for evaluating macroeconomic models that are bound to be mis-specified along several dimensions. Our results yielded plausible estimates for the model parameters, although an examination of the posterior distributions suggested that the data was not informative about a number of parameters. In addition, the cross validation tests suggest that the introduction of a financial accelerator mechanism does improve the model's ability to capture the dynamics observed in the data. Furthermore, we provide evidence that our model with the financial accelerator provides a fit of the data that outperforms a BVAR at more than one lag.

Our results when using the model to examine the conduct of monetary policy-using consumer welfare as the benchmark against which to analyze alternative policies-suggest that the RBI puts a higher than optimal weight

on stabilizing the rate of depreciation of the nominal exchange rate and a 
Figure 6: Path of Key Macroeconomic Variables Under Different Policy Rules
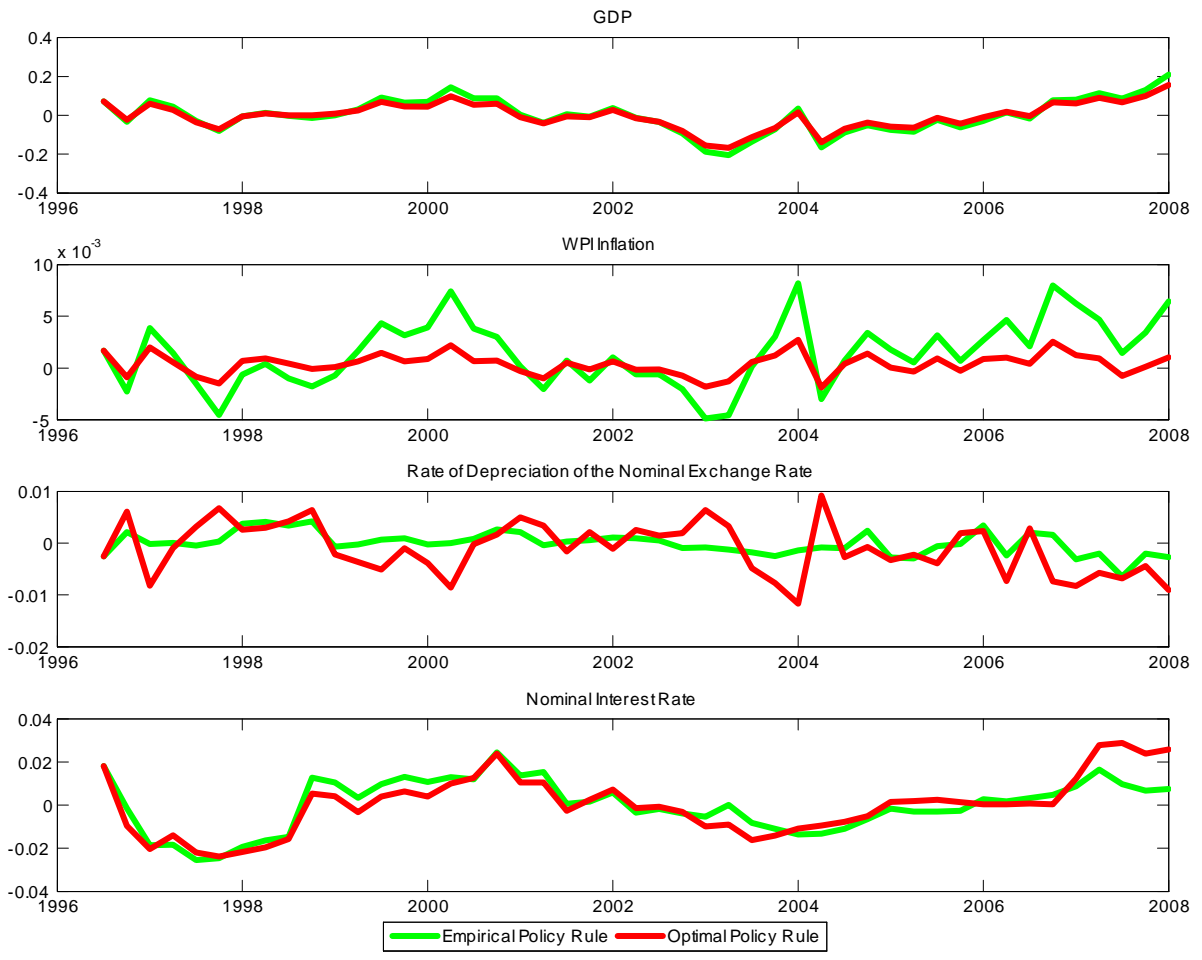
lower than optimal weight on inflation stabilization even in the presence of financial accelerator effects. This comes at the expense of higher inflation volatility as well as higher volatility in the real economy and in financial sector variables. However, exchange rate volatility is substantially lower under the monetary policy reaction function implied by the data relative to the welfare optimizing policy rule. In welfare terms, our analysis suggests that the optimal policy rule entails a welfare gain equivalent to 0.4 percent of permanent consumption relative to the empirical policy rule.

\section{Appendix}

\section{Bibliography}

\section{References}

Aghion, P., P. Bacchetta, and A. Banerjee (2001). Currency crises and monetary policy in an economy with credit constraints. European Economic Review 4\%, 1121-1150.

Ambler, S., A. Dib, and N. Rebei (2004). Optimal taylor rules in an estimated model of a small open economy. Technical report.

Batini, N., P. Levine, and J. Pearlman (2009). Monetary and fiscal rules in an emerging small open economy. Working paper WP/09/22, International Monetary Fund.

Bauwens, L., M. Lubrano, and J.-F. Richard (1999). Bayesian Inference in Dynamic Econometric Models. Princeton: Oxford University Press.

Bernanke, B. and M. Gertler (1989). Agency costs, net worth, and business fluctuations. American Economic Review 79, 14-31.

Bernanke, B., M. Gertler, and S. Gilchrist (1999). The financial accelerator in a quantitative business cycle framework. In Handbook of Macroeconomics. Amsterdam: North Holland.

Bernanke, B. S. and F. S. Mishkin (1997, Spring). Inflation targeting: A new framework for monetary policy? Journal of Economic Perspectives 11(2), 97-116. 
Table 5: Parameter Priors and Posterior Estimates

\begin{tabular}{|c|c|c|c|c|c|c|c|}
\hline \multirow{3}{*}{$\frac{\text { Parameter }}{\gamma_{i}}$} & \multirow{3}{*}{$\frac{\text { Description }}{\text { Interest Rate Smoothing }}$} & \multicolumn{3}{|c|}{ Prior } & \multicolumn{3}{|c|}{ Posterior } \\
\hline & & \multirow{2}{*}{$\frac{\text { Density }}{\text { Beta }}$} & \multirow{2}{*}{$\begin{array}{c}\text { Mean / Min } \\
0.7\end{array}$} & \multirow{2}{*}{$\frac{\text { S.D. } / \mathrm{Max}}{0.2}$} & \multirow{2}{*}{$\begin{array}{c}\text { Mean } \\
0.829\end{array}$} & \multicolumn{2}{|c|}{$90 \%$ Interval } \\
\hline & & & & & & 0.647 & 0.999 \\
\hline$\gamma_{\Pi}$ & Inflation Stabilization & Uniform & 0 & 3 & 0.890 & 0.002 & 1.737 \\
\hline$\gamma_{Y}$ & Output Stabilization & Uniform & -1 & 1 & -0.017 & -0.049 & 0.014 \\
\hline$\gamma_{e}$ & Exchange Rate Stabilization & Uniform & 0 & 3 & 2.438 & 1.852 & 3.000 \\
\hline$b$ & Habit Persistence & Beta & 0.5 & 0.2 & 0.499 & 0.150 & 0.885 \\
\hline$\vartheta_{d}$ & Cost of Non-tradable Goods Price Adjustment & Gamma & 100 & 20 & 118.220 & 84.184 & 151.489 \\
\hline$\vartheta_{m}$ & Cost of Imported Goods Price Adjustment & Gamma & 100 & 20 & 100.043 & 67.992 & 151.489 \\
\hline \multirow[t]{2}{*}{$\phi_{1}$} & Capital Stock Adjustment Costs & Gamma & 12 & 2 & 23.008 & 19.430 & 26.462 \\
\hline & Elasticity of External Finance Premium & Beta & 0.07 & 0.02 & 0.057 & 0.038 & 0.074 \\
\hline$\rho^{\theta}$ & Technology Shock Persistence & Beta & 0.8 & 0.1 & 0.808 & 0.658 & 0.959 \\
\hline$\rho^{i^{*}}$ & Foreign Interest Rate Shock Persistence & Beta & 0.8 & 0.1 & 0.831 & 0.718 & 0.945 \\
\hline$\rho^{\Pi^{*}}$ & Foreign Inflation Shock Persistence & Beta & 0.8 & 0.1 & 0.785 & 0.643 & 0.948 \\
\hline$\rho^{v}$ & Markup Shock Persistence & Beta & 0.8 & 0.1 & 0.860 & 0.731 & 0.978 \\
\hline$\rho^{u i p}$ & UIP Shock Persistence & Beta & 0.8 & 0.1 & 0.794 & 0.654 & 0.931 \\
\hline$\rho^{l}$ & Labour Supply Shock Persistence & Beta & 0.8 & 0.1 & 0.806 & 0.650 & 0.966 \\
\hline$\rho^{c}$ & Marginal Utility Shock Persistence & Beta & 0.8 & 0.1 & 0.810 & 0.658 & 0.959 \\
\hline$\rho^{i n}$ & Investment Efficiency Shock Persistence & Beta & 0.8 & 0.1 & 0.785 & 0.640 & 0.947 \\
\hline$\rho^{Q^{x}}$ & Export Elasticity Shock Persistence & Beta & 0.8 & 0.1 & 0.857 & 0.759 & 0.961 \\
\hline$\rho^{G}$ & Government Spending Shock Persistence & Beta & 0.8 & 0.1 & 0.640 & 0.465 & 0.821 \\
\hline$\rho^{n}$ & Borrowing Cost Shock Persistence & Beta & 0.8 & 0.1 & 0.809 & 0.675 & 0.958 \\
\hline$\rho^{v}$ & Survival Rate Shock Persistence & Beta & 0.8 & 0.1 & 0.805 & 0.656 & 0.958 \\
\hline$\varepsilon^{\theta}$ & Size of Technology Shock & InvGamma & 0.005 & $\operatorname{Inf}$ & 0.005 & 0.001 & 0.009 \\
\hline$\varepsilon^{i^{*}}$ & Size of Foreign Interest Rate Shock & InvGamma & 0.001 & $\operatorname{Inf}$ & 0.001 & 0.000 & 0.002 \\
\hline$\varepsilon^{\Pi^{*}}$ & Size of Foreign Inflation Shock & InvGamma & 0.001 & $\operatorname{Inf}$ & 0.001 & 0.000 & 0.002 \\
\hline$\varepsilon^{v}$ & Size of Markup Shock & InvGamma & 1 & $\operatorname{Inf}$ & 1.198 & 0.270 & 2.219 \\
\hline$\varepsilon^{u i p}$ & Size of UIP Shock & InvGamma & 0.001 & $\operatorname{Inf}$ & 0.001 & 0.000 & 0.002 \\
\hline$\varepsilon^{l}$ & Size of Labour Supply Shock & InvGamma & 0.01 & $\operatorname{Inf}$ & 0.010 & 0.002 & 0.021 \\
\hline$\varepsilon^{c}$ & Size of Marginal Utility Shock & InvGamma & 0.01 & $\operatorname{Inf}$ & 0.016 & 0.003 & 0.028 \\
\hline$\varepsilon^{i}$ & Size of Monetary Policy Shock & InvGamma & 0.005 & $\operatorname{Inf}$ & 0.004 & 0.002 & 0.007 \\
\hline$\varepsilon^{i n}$ & Size of Investment Efficiency Shock & InvGam ma & 0.05 & $\operatorname{Inf}$ & 0.048 & 0.012 & 0.092 \\
\hline$\varepsilon^{Q^{x}}$ & Size of Export Elasticity Shock & InvGamma & 0.1 & $\operatorname{Inf}$ & 0.320 & 0.190 & 0.454 \\
\hline$\varepsilon^{G}$ & Size of Government Spending Shock & InvGamma & 0.01 & $\operatorname{Inf}$ & 0.068 & 0.052 & 0.083 \\
\hline$\varepsilon^{n}$ & Size of Borrowing Cost Shock & InvGamma & 0.001 & $\operatorname{Inf}$ & 0.002 & 0.000 & 0.004 \\
\hline$\varepsilon^{v}$ & Size of Survival Rate Shock & InvGamma & 0.001 & $\operatorname{Inf}$ & 0.002 & 0.000 & 0.004 \\
\hline
\end{tabular}


Carlstrom, G. and T. Fuerst (1997). Agency costs, net worth, and business fluctuations. American Economic Review 87, 893-910.

Christensen, I. and A. Dib (2006). Monetary policy in an estimated dsge model with a financial accelerator. Technical report.

Christiano, L., R. Motto, and M. Rostagno (2007, October). Shocks, structures or monetary policies? the euro area and us after 2001. NBER Working Papers 13521, National Bureau of Economic Research, Inc.

Clarida, R., J. Gali, and M. Gertler (1999). The science of monetary policy: A new Keynesian perspective. Journal of Economic Literature XXXVII.

Dib, A., C. Mendicino, and Y. Zhang (2008). Price level targeting in a small open economy with financial frictions: Welfare analysis. Technical report.

Elekdag, S., A. Justiniano, and I. Tchakarov (2005). An estimated small open economy model of the financial accelerator. Working paper WP/05/44, International Monetary Fund.

Fernandez-Villaverde, J. and J. Rubio-Ramirez (2004). Comparing dynamic equilibrium models to data: A Bayesian approach. Journal of Econometrics 123, 153-187.

Gertler, M., S. Gilchrist, and F. M. Natalucci (2007, 03). External constraints on monetary policy and the financial accelerator. Journal of Money, Credit and Banking 39(2-3), 295-330.

Geweke, J. (1998). Using simulation methods for Bayesian econometric models: Inference, development and communication. Staff Report 249. Federal Reserve Bank of Minneapolis.

IMF (2009, October). World Economic Outlook. Washington: International Monetary Fund.

Ireland, P. (2001). Sticky-price models of the business cycle: Specification and stability. Journal of Monetary Economics 47, 3-18.

Ireland, P. N. (2003, November). Endogenous money or sticky prices? Journal of Monetary Economics 50(8), 1623-1648.

Juillard, M. (2001, April). Dynare: A program for the simulation of rational expectation models. Computing in Economics and Finance 2001 213, Society for Computational Economics. 
Julliard, M., P. Karam, D. Laxton, and P. Pesenti (2004). Welfare-based monetary policy rules in an estimated DSGE model of the U.S. economy. mimeo. Federal Reserve Bank of New York.

Kiyotaki, N. and J. Moore (1997, April). Credit cycles. Journal of Political Economy 105(2), 211-48.

Kollmann, R. (2002). Monetary policy rules in the open economy: Effects on welfare and business cycles. Journal of Monetary Economics 49, 989-1015.

Krugman, P. (1999). Balance sheets, the transfer problem, and financial crises. International Tax and Public Finance 6, 459-472.

Leith, C., I. Moldovan, and R. Rossi (2009, July). Optimal monetary policy in a new keynesian model with habits in consumption. Working Paper Series 1076, European Central Bank.

Ljungqvist, L. and T. J. Sargent (2004, January). Recursive Macroeconomic Theory, 2nd Edition, Volume 1 of MIT Press Books. The MIT Press.

Lubik, T. and F. Schorfheide (2005). A Bayesian look at new open economy. mimeo.

Mohan, R. (2004). Challenges to monetary policy in a globalizing context. RBI Bulletin $2004 a$.

Mohanty, M. S. and M. Klau (2004, March). Monetary policy rules in emerging market economies: issues and evidence. BIS Working Papers 149, Bank for International Settlements.

Oura, H. (2008, March). Financial development and growth in india: A growing tiger in a cage? IMF Working Paper 08/79. (Washington: International Monetary Fund).

Rajan, R. (2008). A hundred small steps: Report on the committee on financial sector reforms. Technical report, Planning Commission, Government of India.

RBI (2009). The evolution of monetary policy, 2003-04. Special volume of its reports on currency and finance (volume i), Reserve Bank of India.

Rotemberg, J. (1982). Sticky prices in the United States. Journal of Political Economy 90, 1187-1211. 
Saxegaard, M. (2006a). Fiscal and monetary policy in an estimated model of the philippine economy. Manuscript.

Saxegaard, M. (2006b). Monetary policy rules in a small open economy with external liabilities. Manuscript.

Schmitt-Grohe, S. and M. Uribe (2003). Closing small open economy models. Journal of International Economics 61, 163-185.

Schmitt-Grohe, S. and M. Uribe (2004). Solving dynamic general equilibrium models using a second-order approximation to the policy function. Journal of Economic Dynamics and Control 28, 755-775.

Schmitt-Grohe, S. and M. Uribe (2007, September). Optimal simple and implementable monetary and fiscal rules. Journal of Monetary Economics 54 (6), 1702-1725.

Schorfheide, F. (2000). Loss function-based evaluation of DSGE models. Journal of Applied Econometrics 15, 645-670.

Sims, C. A. and T. Zha (1998, November). Bayesian methods for dynamic multivariate models. International Economic Review 39(4), 949-68.

Smets, F. and R. Wouters (2003). An estimated dynamic stochastic general equilibrium model of the Euro area. Journal of European Economic Association 1, 1123-1175.

Smets, F. and R. Wouters (2005). Comparing shocks and frictions in U.s. and Euro area business cycles: A Bayesian DSGE approach. Journal of Applied Econometrics 20(2), 161-183. 